\title{
Therapeutic Ophthalmic Lenses: A Review
}

\author{
Nadia Toffoletto ${ }^{1, *(1)}$, Benilde Saramago ${ }^{1}$ and Ana Paula Serro ${ }^{1,2}$ (i) \\ 1 Centro de Química Estrutural, Instituto Superior Técnico, University of Lisbon, Av. Rovisco Pais, \\ 1049-001 Lisbon, Portugal; b.saramago@tecnico.ulisboa.pt (B.S.); anapaula.serro@tecnico.ulisboa.pt (A.P.S.) \\ 2 Centro de Investigação Interdisciplinar Egas Moniz, Instituto Universitário Egas Moniz, Quinta da Granja, \\ Monte de Caparica, 2829-511 Caparica, Portugal \\ * Correspondence: nadia.toffoletto@tecnico.ulisboa.pt
}

Citation: Toffoletto, N.; Saramago, B.; Serro, A.P. Therapeutic Ophthalmic Lenses: A Review. Pharmaceutics 2021, 13, 36. https://doi.org/10.3390/ pharmaceutics 13010036

Received: 12 November 2020 Accepted: 17 December 2020 Published: 28 December 2020

Publisher's Note: MDPI stays neutral with regard to jurisdictional clai$\mathrm{ms}$ in published maps and institutional affiliations.

Copyright: (C) 2020 by the authors. Licensee MDPI, Basel, Switzerland. This article is an open access article distributed under the terms and conditions of the Creative Commons Attribution (CC BY) license (https:// creativecommons.org/licenses/by/ $4.0 /)$.

\begin{abstract}
An increasing incidence of eye diseases has been registered in the last decades in developed countries due to the ageing of population, changes in lifestyle, environmental factors, and the presence of concomitant medical conditions. The increase of public awareness on ocular conditions leads to an early diagnosis and treatment, as well as an increased demand for more effective and minimally invasive solutions for the treatment of both the anterior and posterior segments of the eye. Despite being the most common route of ophthalmic drug administration, eye drops are associated with compliance issues, drug wastage by lacrimation, and low bioavailability due to the ocular barriers. In order to overcome these problems, the design of drug-eluting ophthalmic lenses constitutes a non-invasive and patient-friendly approach for the sustained drug delivery to the eye. Several examples of therapeutic contact lenses and intraocular lenses have been developed, by means of different strategies of drug loading, leading to promising results. This review aims to report the recent advances in the development of therapeutic ophthalmic lenses for the treatment and / or prophylaxis of eye pathologies (i.e., glaucoma, cataract, corneal diseases, or posterior segment diseases) and it gives an overview of the future perspectives and challenges in the field.
\end{abstract}

Keywords: therapeutic contact lenses; therapeutic intraocular lenses; eye diseases; glaucoma; cataract; corneal diseases; posterior segment of the eye diseases

\section{Introduction}

A global increase in the number of people with an eye condition has been registered in the last decades, according to the WHO World Report on Vision 2019. While cataract remains the main cause of visual impairment in developing countries [1], the ageing of population increased the incidence of chronic posterior eye diseases (e.g., age-related macular degeneration (AMD)), glaucoma, and cataract [2]. Increased levels of air pollution, the prolonged use of steroids, and the increased incidence of allergic diseases are associated with disorders of the ocular surface, such as keratoconjunctivitis sicca or dry eye disease [3,4]. Other medical conditions, such as rheumatoid arthritis, multiple sclerosis, and diabetes, also present repercussions in the eye. Systemic microvascular damages that are associated to diabetes, in fact, affect both the anterior and posterior segment of the eye and they can lead to corneal issues, tear film instability, increased intraocular pressure, and a higher incidence of glaucoma, cataract, and uveitis, as well as pathologies of the back of the eye, such as diabetic retinopathy (DR) and diabetic macular edema (DME) [5]. Consequently, diabetic patients are 25 times more likely to become blind than the general population [6].

The public awareness on eye diseases is increasing, leading to an early diagnosis and the treatment of ocular pathologies as well as an increased demand for more effective and patient-friendly solutions. The local treatment of the eye is advantageous relative to systemic drug administration, since it avoids high concentrations of drug in the blood circulation and eventual undesirable side effects in other organs. Among the several possibilities for ocular drug administration (Figure 1), eye drops are the easiest route 
for topical delivery. However, this methodology is associated with compliance issues, especially in the case of elderly patients, who could have a limited ability to strictly adhere to the prescribed treatment [7]. After cataract surgery, for example, complex prophylaxis regimes are often adopted: it is not uncommon to prescribe a combination of three different drugs that are to be administered in multiple drops, several times a day, for a few weeks [8]. It was estimated that cataract surgery patients only apply half of the prescribed number of drops [9]. Compliance problems are also registered in glaucoma patients, as multiple formulations of topical drops for several years are commonly needed [10]. Other issues are the improper administration of topical medications, such as drops missing the eye, the delivery of an incorrect number of drops, and the contamination of the bottle tip [8]. Moreover, in order to avoid drug wash-out, it is suggested to wait $5 \mathrm{~min}$. between two subsequent topical applications, but less than half of the patients complies with this recommendation [11]. Concerns also arise from the drug wastage by lacrimation and systemic absorption when topical administration is performed. The instillation of drops at fixed intervals causes a high variability of the intraocular drug concentration during the therapeutic treatment, which would be avoided with a continuous drug release. All of this, combined with the limited ability of the cornea to absorb drugs (at most, 5\% bioavailability in optimal conditions [12-14], e.g., moderately lipophilic and moderately charged drugs, low molecular weight, the presence of permeation enhancers in the topical formulation $[13,15,16])$, contributes to the low efficiency of eye drop administration [17]. Ocular injections (e.g., intravitreal, intracameral, subconjunctival, and sub-tenon injections) are considered an alternative route to increase the efficacy of drug delivery, in particular to the posterior segment of the eye. However, injections lead to an initial high peak of ocular drug concentration followed by rapid decay $[18,19]$. While the use of biodegradable drugeluting intraocular implants could overcome this issue and sustain drug release for several months, any form of ocular injection or ocular implant remains invasive for the patient and it is associated to a higher risk of adverse events when compared to eye drops [20].

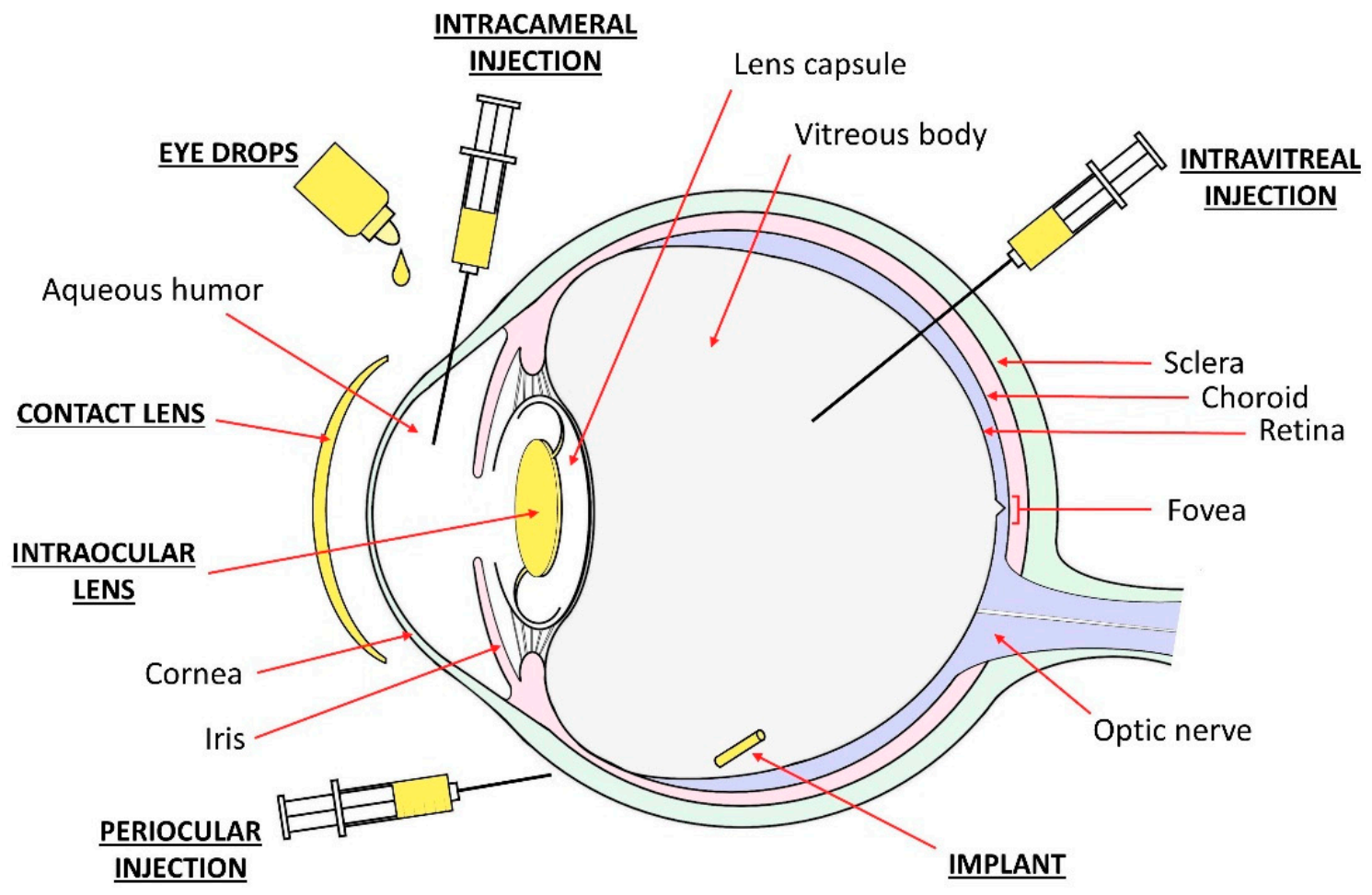

Figure 1. Ocular drug administration routes: eye drops, therapeutic contact lenses, therapeutic intraocular lenses, periocular injections (e.g., subconjunctival or sub-tenon injections), drug-eluting implant, intravitreal, and intracameral injections. 
In the last decade, increasing interest has grown toward to the possibility of designing drug-eluting ophthalmic lenses able to guarantee a sustained drug delivery to the eye in a non-invasive manner. Drug-eluting contact lenses (CLs) may avoid the frequent administration of eye drops and, therefore, increase patient's comfort and compliance. By increasing the drug residence time on the cornea, the drug bioavailability is increased, while the necessary drug dose for achieving a therapeutic effect is reduced. Consequently, a lower systemic drug absorption is expected when compared to eye drops [21,22]. On the other hand, drug-eluting intraocular lenses (IOLs), implanted e.g., during cataract surgery, allow for overcoming the corneal permeability barrier by delivering drug directly into the aqueous humor, and sustaining drug release for weeks after surgery [23,24]. While CLs can be often replaced and are, therefore, suitable for both short-term and prolonged treatments, drug-eluting IOLs are a one-time treatment for the management of acute symptoms (associated, for example, with ocular inflammation after surgery $[25,26]$ ) or for the temporary replacement of the frequent and invasive intraocular drug injections to which chronic patients are often subjected [27].

Concerning CLs, patient compliance with good wear practices is often referred as a concern. The difficulty to place the CL in the eye, the eventual discomfort, the need of lens care and hygiene practices, and the need of fulfilling lens wear and/or replacement schedules are pointed to as the main reasons for the lack of compliance. However, a significant expansion of the number of wearers worldwide has been observed in the last two decades, nowadays reaching over 150 million people [28,29]. The evolution on the production technology of these devices, that turn them more comfortable, the implementation of a better patient's education from the start of the lens-wearing and a close monitoring by practitioners were critical factors to enhance the adhesion to CLs. Moreover, the perception that the CLs are a prescribed medical device, and not just a commodity, and that they can be used for 'treatment', significantly increased the openness to their use. The previous use of CLs for refractive error correction, with all the knowledge of the required associated procedures, shall facilitate the acceptance of these devices as drug delivery vehicles among the patients.

The main goal of this review is to gather information on therapeutic ophthalmic lenses that have been developed in the last 10 years. First, the different drug loading methods adopted to tune the release profile of the lenses will be addressed. Subsequently, a vast number of examples will illustrate the potential of these innovative non-invasive drug delivery devices for the treatment and/or prophylaxis of glaucoma, cataract, corneal diseases, or posterior segment diseases. Finally, an overview of the future perspectives and challenges in the field will be given.

\section{Methodology}

The Scopus electronic database was consulted on 15 April 2020. The following search terms were used: lens AND drug release AND diabetic eye; lens AND drug release AND glaucoma; lens AND drug release AND diabetic cornea OR keratopathy OR dry eye OR keratitis OR edema OR keratoconus OR corneal dystrophy; lens AND drug release AND cataract prevention OR endophthalmitis OR inflammation OR infection OR PCO OR posterior opacification; and, lens AND drug release AND back of the eye OR posterior segment OR retina OR retinopathy OR vitreous OR macula.

Journal articles describing therapeutic ophthalmic lenses and published after 1 January 2010 were collected and analyzed. Only results that were published in English language were considered.

\section{Drug Loading Methods}

In the following section, the various strategies that have been developed for loading drugs in therapeutic lenses are summarized. In Figure 2, a schematic description of these methods is presented. 


\subsection{Soaking}

The simplest method for obtaining therapeutic lenses is soaking into a drug solution [24,30-45]. The amount of drug loaded and released depends on the material and the structure of the lens (e.g., porosity, swelling capacity), on the drug characteristics (e.g., molecular structure, molecular weight, charge), and on eventual interactions that may be established between the drugs and the lens material [22]. Besides, the soaking parameters also affects drug loading, i.e., the concentration of the solution [46], loading time [40], and environmental factors, such as temperature and $\mathrm{pH}$ [47]. The main issue of the soaking method still is the limited control over the drug release profile, which is usually characterized by a high initial release rate and a short delivery time after lens placement onto the eye $[47,48]$. Furthermore, economic and environmental concerns rise due to the waste of the drug present in the soaking solution [46]. Most drug-loaded lenses that are obtained by soaking are able to retain their therapeutic effect for a few hours or for some days [48], although a few examples of sustained release over weeks do exist [24]. This fast release kinetics could be suitable in the case of disposable CLs with a daily use, but it is not compatible with the development of IOLs with a long-term therapeutic purpose [49].

SOAKING

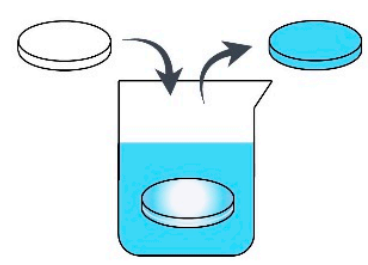

COATING

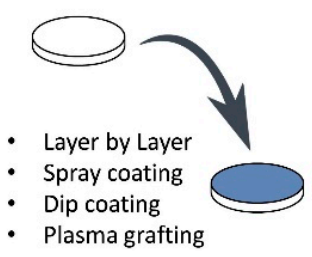

INCORPORATION OF FUNCTIONAL MOLECULES

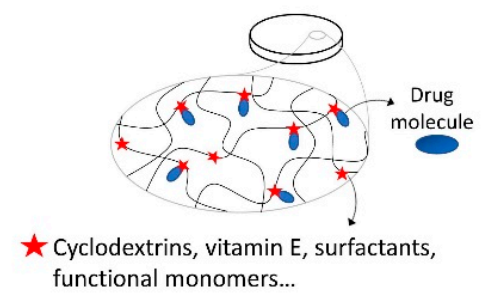
functional monomers...

\section{MOLECULAR IMPRINTING}

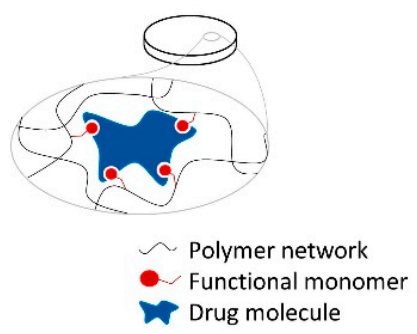

DRUG RESERVOIRS

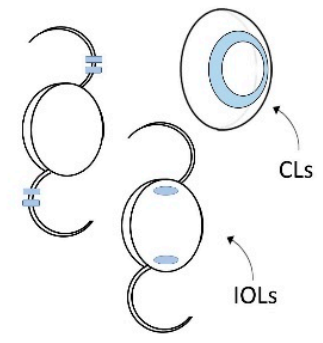

Figure 2. Strategies for the development of therapeutic ophthalmic lenses: soaking into a drug solution, incorporation of functional molecules with a high affinity to the drug, molecular imprinting, drug-eluting or drug-barrier coating, supercritical impregnation, incorporation of nanocarriers and incorporation of drug reservoirs.

\subsection{Incorporation of Functional Molecules}

The incorporation of functional molecules into the lens polymer (e.g., cyclodextrins, vitamin E, surfactants, functional monomers) proved to be a potential strategy for enhancing drug loading during the soaking step and tuning the release kinetics. Cyclodextrins present a hydrophobic cavity that is suitable for accommodating hydrophobic drugs. They have been successfully co-polymerized with the lens backbone material to control drug delivery over time $[25,50]$, or mixed to the drug solution prior to lens soaking in order to enhance the apparent aqueous solubility of hydrophobic drugs [51]. Vitamin E is considered to be a promising molecule for providing a hydrophobic diffusion barrier for the release of hydrophilic drugs [52-56]. When hydrophobic drugs are involved, drug molecules diffuse through the highly viscous vitamin E agglomerates, resulting in a slower release kinetic [57]. Because of the hydrophobic nature of vitamin E, it can be easily incorporated 
into the lenses by soaking in a vitamin E-ethanol solution. After ethanol evaporation, vitamin agglomerates remain trapped into the polymer network. However, a loss in oxygen permeability, protein adsorption, and changes in the mechanical properties can be associated with the use of this functional molecule in therapeutic lenses [22]. Aggregates that are composed of long-chain surfactants and oppositely charged ionic drugs can be added to the lens pre-polymer mixture to extend drug release over time by entrapment of the drug molecules [58]. The suitability of the lens polymer network to load and release drugs in a sustained fashion can also be improved by co-polymerization with functional monomers presenting a stronger affinity with the target drugs [59-61] or by the modification of the lens charge $[62,63]$.

\subsection{Coating}

Several methods have been suggested to produce coatings on drug-eluting biomedical devices (e.g., layer-by-layer deposition, spray coating, dip coating, plasma-assisted grafting) with the purpose of implementing drug-eluting reservoirs [64-73]. Besides, these coatings may be used in order to increase the hydrophilicity of the device surface [74] and, also, as diffusion barriers to drug release [75-77]. The main concern with the design of coatings to be applied onto CLs or IOLs is the preservation of the optical properties of the original lenses. In the case of coatings with biodegradable polymers, the degradation products must be biocompatible with the surrounding tissues. Furthermore, the coating adhesion to the lens material should be sufficient for avoiding the presence of floating debris on the cornea or in the anterior chamber, which results from the coating detachment from CLs or IOLs, respectively.

\subsection{Molecular Imprinting}

Molecular imprinting can be obtained by two different methods, which involve either covalent or noncovalent bonds (e.g., ionic, hydrophobic, hydrogen bonds) between the template drug and functional monomers. The latter method is the most widely used in drug delivery, as it is associated to an easier and faster drug dissociation kinetics. Stable noncovalent drug-monomer complexes are established by solubilizing both the template drug and the functional monomers in the prepolymer mixture [78]. With the subsequent polymerization step, the functional monomers are covalently bonded to the polymer backbone, but not the drug, due to the presence of aromatic rings or other highly stable molecular structures that are less prone to react. The drug is removed during the washing cycles to which the newly polymerized biomaterials are subjected to eliminate potentially toxic unreacted monomers [79]. After drug removal, tailored memory sites remain imprinted in the polymer and, by mimicking the drug's natural receptors, they create an oriented functional material with high affinity to the template drug [80]. The drug is then re-loaded in the polymer by soaking and interacting with the memory sites. This process can lead to a higher drug loading and a slower release profile [81], and it was successfully applied to therapeutic CLs and IOLs [82-88]. The use of miscible combinations of drugs and monomers is generally preferable over non-miscible ones in order to avoid the use of solvents, since their presence could prevent the orientation of monomers around the drug molecules and result in a less effective imprinting [89]. The drug affinity and the release kinetics are determined by the type of functional monomers and their concentration in the matrix: the ratio between functional monomers and drug molecules must be optimized for each combination of drug and monomers [22,89-91]. This ratio has to be sufficiently high to create enough interactions and retard drug release; however, an excessive monomer concentration could interfere with drug diffusion during the loading phase and could also impede an organized orientation of molecules, thus hindering any effect on the template drug. 


\subsection{Supercritical Impregnation}

Supercritical fluids are characterized by a high density, low viscosity, high diffusivity, and low interfacial tension [92]. These features are favorable for the diffusion of such fluids in the polymer matrices of CLs or IOLs [26,60,92-97]. Impregnation with a supercritical fluid consists in the dissolution of the drug in the solvent (generally supercritical $\mathrm{CO}_{2}$ ), followed by the interaction with the target material [22]. Supercritical $\mathrm{CO}_{2}$ is a better solvent for drugs than water, and also a better plasticizer for polymer networks: therefore, drug loading is enhanced when compared to traditional techniques like soaking [46]. This method is considered a 'green' alternative, as it forces the impregnation of the drug in the lens without using organic solvents. Moreover, $\mathrm{CO}_{2}$ is spontaneously released from the lens after impregnation, avoiding the purification steps that are usually associated to the use of solvents [92]. An optimized loading and release can be obtained by tuning the processing parameters, like pressure, temperature, presence of a co-solvent, duration of impregnation, and depressurization rate [22,46]. The choice of suitable parameters is fundamental: a too rapid depressurization, for example, can damage the lens material (foaming phenomenon [26]) and, therefore, compromise the optical functionality of the device. However, a too slow depressurization limits the efficacy of impregnation, as it reduces drug deposition into the polymer network [98]. The complex set-up is a limitation in the use of supercritical impregnation, as compared to other drug-loading techniques, and it can hinder its incorporation into the manufacturing process [89].

When applied to IOLs, supercritical impregnation allowed obtaining a sustained drug release over several weeks with various types of drugs (e.g., dexamethasone sodium and ciprofloxacin [26,92,95], methotrexate [97], cefuroxime sodium, and timolol maleate [98]). However, when the technology was applied to the thinner CLs, an initial burst release was commonly detected, followed by a sustained release for a few hours $[93,94,99]$. In order to overcome this issue, the combination of molecular imprinting and impregnation demonstrated to be an interesting alternative for the achievement of a gradual release, even in the first hours of CL wearing [100].

\subsection{Incorporation of Nanocarriers}

Colloidal nanocarriers entrapping active substances (e.g., polymeric biodegradable or non-degradable nanoparticles [74,101-108], liposomes, microemulsions, micelles) can be easily incorporated into the polymeric matrix of the lens [22]. Most of the nanoparticles for drug-delivery (homogeneous nanospheres or heterogeneous nanocapsules) are biodegradable polymers, which can release the drugs by degradation. Other mechanisms, such as light-induced release, can be implemented on non-degradable carriers [109]. Changes in $\mathrm{pH}$ and temperature, drug diffusion through the particle core/shell and matrix swelling also influence the drug delivery profile [110]. Liposomes have a structure that is similar to the biological membranes, in which lipophilic drugs can be loaded into the phospholipid bilayer and hydrophilic drugs into the aqueous core [111]. Polymeric micelles are spontaneously formed structures with promising applications in the delivery of hydrophobic drugs [112,113]. Microemulsions increase the drug-loading capacity during soaking and they present good thermodynamic stability, while preserving the ease of fabrication of the therapeutic lenses [114-116].

Despite the advantages of these innovative systems, significant problems need to be overcome during their design as drug-carriers for ophthalmic applications. In fact, changes in the mechanical properties and water content can be associated to their use in hydrogels [22]. Moreover, their natural tendency to aggregation must be hampered in order avoid a decrease in transparency [10]. 


\subsection{Drug Reservoirs}

Drug-eluting ocular implants have long been used as drug delivery platforms. However, their eventual migration after injection in the eye is one possible complication. The physical link of these implants to IOLs may overcome the problem and guarantee their correct positioning in the anterior chamber of the eye. Despite being more commonly applied on IOLs [23,27,117-119], examples of incorporated reservoirs were also implemented on CLs [120-126]. Drug reservoirs are usually constituted of biodegradable polymers: the material must be biocompatible, and its degradation products should not cause chronic inflammation or toxicity in the ocular tissues [47]. Reservoirs guarantee a prolonged (usually months) and controlled release over time. Moreover, the optical properties of the lens are not compromised, as they can be attached to the haptics of IOLs or incorporated into the peripheral part of CLs [12]. On the other hand, the design and fabrication of reservoirs can be complex and the physical link with the lens might be difficult to manage [46]. In the case of IOLs, the presence of these reservoirs can also raise problems while loading the lens in the injector system prior to surgery or in the ejection process [47].

\section{Lenses for Ocular Diseases}

\subsection{Glaucoma}

Glaucoma is the leading cause of irreversible blindness worldwide, and it is characterized by a progressive visual field loss due to the degeneration of retinal ganglion cells and optic nerve changes $[5,127]$. Although the relationship between diabetes and the development of glaucoma is still controversial and further investigation is needed, recent studies $[128,129]$ have shown a significantly higher intraocular pressure (IOP) in diabetic patients when compared to non-diabetics, possibly due to an impaired autonomic function [129] and the progression of microvascular injury that is associated with chronic hyperglycemia [130]. An elevated IOP is considered to be a major risk factor for glaucoma, as it is associated to retinal ischemia and mechanical stress, as well as to an impaired ocular blood flow to retinal neurons [128].

The current treatment of glaucoma involves the lowering of IOP by pharmacological administration, laser, or surgical procedures [131]. The balance between the aqueous humor production and outflow from the anterior chamber of the eye regulates the IOP [128]. Therefore, current drug treatments are targeted at the reduction of aqueous humor production and/or the increase of the outflow facility. This can be achieved by use of beta-adrenergic antagonists (e.g., timolol, betaxolol, puerarin), sympathomimetic agents (e.g., epinephrine), parasympathomimetic miotic agents (e.g., pilocarpine), carbonic anhydrase inhibitors (e.g., dorzolamide), or prostaglandin analogues (e.g., latanoprost, bimatoprost) [132].

Topical drug application using eye drops is the first-line treatment [133]. However, an accurate drug administration is required in order to maintain a constant physiological IOP (generally 10-21 mmHg) [134]. Because of the chronic nature of the pathology and the reported poor patient adherence to the therapy [133], new drug delivery methods have recently attracted increased interest, including drug eluting CLs (Table 1).

Drug loading by soaking the material in a drug solution has been widely investigated for the treatment of glaucoma with therapeutic CLs [30]. In particular, different strategies were tested in order to increase the drug solubility in the loading solution and the drug amount loaded into the devices. Xu et al. [61], for example, co-polymerized $n$ vinylpyrrolidone (NVP), a hydrotropic agent, into pHEMA-based CLs in order to enhance puerarin solubilization into the hydrogel during the soaking phase. A six-fold increased residence time of puerarin in a rabbit eye model was obtained from NVP-modified CLs, as compared to traditional eye-drops. Xu et al. [115] and Wei et al. [116] suggested the use of microemulsions as soaking solutions to enhance the loading of bimatoprost and timolol, respectively: drug release was sustained up to $96 \mathrm{~h}$ in vitro, and a prolonged reduction of the IOP was observed in rabbits. García-Fernández et al. [51] evidenced that the incorporation of ethoxzolamide, a hydrophobic carbonic anhydrase inhibitor, in poly-cyclodextrins carriers enhanced the drug solubility in the aqueous soaking solution and its loading 
into HEMA-based CLs, while leading to a controlled release profile in vitro. Similarly, the addition of gold nanoparticles (GNP), either in the soaking solution or the polymer composition, resulted in a higher amount of timolol loaded into HEMA-based lenses. The presence of GNP in the lenses also augmented the drug deposition in the ciliary muscle of rabbits, where the majority of beta-receptors are located [107]. The time waste during drug loading is one of the disadvantages of the soaking method. However, Horne et al. [38] recently suggested a rapid soaking of commercial silicone hydrogel CLs (4 min.) into a non-aqueous solvent ( $n$-propanol) to load latanoprost, a hydrophobic drug. $N$-propanol acted as a better solvent for the CLs than water, and the subsequent drug uptake correlated with the amount of lens swelling independently on the interactions between the lens material and the drug. Drug deposition in the lens and propanol removal was then obtained by washing in water, which is a non-solvent for the hydrophobic latanoprost. The release in artificial tear solution lasted over days.

Table 1. Therapeutic ophthalmic lenses developed between 2010 and 2020 suitable for the treatment of glaucoma.

\begin{tabular}{|c|c|c|c|c|}
\hline Pharmacological Action & Drugs & Lens Type & Backbone Monomers & Ref. \\
\hline \multirow{15}{*}{ Beta-adrenergic antagonist } & \multirow{13}{*}{ Timolol } & \multirow{13}{*}{ CL } & HEMA & {$[82,102,113]$} \\
\hline & & & HEMA-MAA & {$[86,93,103,121,135]$} \\
\hline & & & HEMA-PVP & {$[54,93,136]$} \\
\hline & & & HEMA-PC & [93] \\
\hline & & & HEMA-DMA/GMA/Sil & {$[104,137]$} \\
\hline & & & Sil-DMA & [55] \\
\hline & & & Sil-DMA-MAA-PVP & [101] \\
\hline & & & Sil-DMA-HEMA & [116] \\
\hline & & & Sil-DMA-HEMA-PVP & {$[56,107,122,123]$} \\
\hline & & & Sil-DMA-HEMA-PVP-PDMS & {$[52,101]$} \\
\hline & & & Sil-PVP & {$[67-69,94]$} \\
\hline & & & PDMS & [126] \\
\hline & & & Modified PVA & [93] \\
\hline & Betaxolol & $\mathrm{CL}$ & Sil-HEMA-PVP & [138] \\
\hline & Puerarin & CL & HEMA-PVP-MA & [61] \\
\hline Sympathomimetic agents & Brimonidine & $\mathrm{CL}$ & HEMA-PVP & [54] \\
\hline \multirow{9}{*}{ Carbonic anhydrase inhibitors } & Dorzolamide & CL & Sil-DMA-HEMA-PVP-PDMS & [52] \\
\hline & \multirow{3}{*}{ Ethoxzolamide } & \multirow{2}{*}{ CL } & HEMA & {$[51,84]$} \\
\hline & & & PVP-DMA & {$[85]$} \\
\hline & & & & \\
\hline & \multirow{5}{*}{ Acetazolamide } & \multirow{5}{*}{ CL } & HEMA & [84] \\
\hline & & & PVP-DMA & [85] \\
\hline & & & HEMA-PC/MAA/PVP & [93] \\
\hline & & & Modified PVA & [93] \\
\hline & & & Sil-PVP & [94] \\
\hline \multirow{8}{*}{ Prostaglandin analogues } & \multirow{5}{*}{ Latanoprost } & \multirow{5}{*}{ CL } & HEMA & {$[38,113]$} \\
\hline & & & HEMA-MAA & {$[124,125]$} \\
\hline & & & Sil-DMA/PVP & [38] \\
\hline & & & Sil-DMA-HEMA-PVP(-PDMS) & {$[38,53]$} \\
\hline & & & Sil-IBM-PVP-HBM-MVA & [38] \\
\hline & \multirow{3}{*}{ Bimatoprost } & \multirow{3}{*}{ CL } & Sil-DMA-HEMA & [115] \\
\hline & & & Sil-DMA-HEMA-MAA & [83] \\
\hline & & & Sil-DMA-HEMA-PVP(-PDMS) & {$[53,123]$} \\
\hline
\end{tabular}

The group of Chauhan used a pre-soaking in a vitamin E-ethanol solution, prior to soaking in the timolol-PBS solution, in order to form aggregates that have a barrier effect on drug diffusion from commercial silicone lenses $[55,56]$. In glaucomatous dogs, CLs 
containing vitamin E released timolol with the same efficacy of eye drops, but with reduced drug loss. The same group developed dual-drug delivering lenses [52] while using vitamin E presoaking: the simultaneous loading of timolol and dorzolamide increased the release duration of both drugs up to two days. A superior IOP reduction was observed with CLs in dogs, as compared to eye drops administration. Moreover, the effect on IOP lasted for one week after removal of the device, which is promising for future clinical applications. Vitamin E presoaking was also adopted in order to increase the delivery duration of bimatoprost up to 10 days in vitro [53]. Lee et al. [54] experimented the simultaneous loading of vitamin $\mathrm{E}$ or vitamin A and anti-glaucoma drugs (i.e., timolol or brimonidine) on hydrophilic HEMA-based CLs: the treatment enhanced drug loading, but no effects on the release kinetic were detected. Lee et al. did not provide an explanation for this behavior, but it may be related to the fact that vitamin E precipitates at the interfaces of the biphasic silicone material and the transport of the drug is a combination between diffusion in the aqueous phase and surface diffusion over the vitamin E aggregates [139]. In contrast, the monophasic HEMA material does not provide preferential sites for the adsorption of vitamin E agglomerates, which will not affect drug release.

In other cases, drugs were incorporated inside the lens material during the polymerization step while using micro or nanocarriers. A 48-h release in vitro was obtained by including timolol-loaded ethyl cellulose microparticles into the polymer mixture [135]. The addition of timolol-loaded PGT (propoxylated glyceryl triacylate) or EGDMA (ethylene glycol dimethacrylate) nanoparticles resulted in a sustained release in vitro for over 20 days, even after five months of packaging in refrigerator [101,102]. The incorporation of mPEG-PLA (methoxy poly(ethylene glycol)-poly(D,L-lactide)) micelles allowed for the simultaneous release of timolol and latanoprost for $120 \mathrm{~h}$ and $96 \mathrm{~h}$, respectively, and a reduction of IOP for over $168 \mathrm{~h}$ in rabbits [113].

Molecular imprinted CLs were also successfully studied: uptake and release kinetics of timolol [82], bimatoprost [83], ethoxzolamide, and acetazolamide [84,85] were positively influenced by the presence of imprinted domains in the lens material, without significant affection of the CL properties. Timolol was released up to $90 \mathrm{~h}$ in vitro, due to the interactive sites between the drug and HEMA, carboxy-methyl chitosan, and acrylamide, which compose the CL material. Bimatoprost was released up to 36-60 h in vitro, and a low initial burst release was observed in rabbit tear fluid when compared to eye drops administration and non-imprinted drug-loaded CLs. Interestingly, Deng et al. [86] developed a structuralcolored timolol-imprinted CL, which was able to shift from green to blue with timolol release, by using a monodispersed silica nanoparticles mold. Imprinting with methacrylic acid increased the loading amount and the residence time of the drug (up to $12 \mathrm{~h}$ ), while the binding and unbinding of timolol molecules caused changes in the volume and refractive index of the material, which is translated into an optical signal for the monitoring of drug release.

Costa et al. $[93,94]$ applied the supercritical solvent impregnation technology to the drug loading of commercial CLs: the amount of timolol maleate (TM) and acetazolamide loaded into the lenses was tuned by adopting different solvent mixtures and parameters, without alterations of the CL features. However, an initial burst characterized the release profile and it was not sustained over time.

More recently, the group of Ahmad [67] fabricated drug-loaded coatings on CLs while using various techniques: timolol-loaded PNIPAM (poly- $n$-isopropylacrylamide) and/or PVP (polyvinylpyrrolidone) coatings were obtained by electrohydrodynamic atomization, an electrically driven spraying process, and released TM for hours in vitro. Similar results were obtained by electrospinning PVP-PNIPAM-TM solutions incorporating corneal permeation enhancers [68]. In another study [69], chitosan and borneol were incorporated in PVP-PNIPAM-TM atomized coatings as a release modulator and a permeation enhancer, respectively. Chitosan also acted as a permeation enhancer, and increased TM release by up to $23 \%$. However, in all cases, the presence of a mask during coating deposition was necessary to preserve the optical functionality of the central part of the lenses. 
Examples of polymeric ring-shaped drug reservoirs have been designed to be separately fabricated and subsequently incorporated in CLs. The implantation of ethyl cellulose nanoparticle-laden rings [121] in HEMA/MAA CLs sustained TM release for $168 \mathrm{~h}$ in vitro and caused a significant IOP reduction in rabbits for $192 \mathrm{~h}$. The dual-delivery of timolol and hyaluronic acid, a comfort agent, was obtained from HEMA/DMA-based rings [122] with comparable results: timolol was detected in rabbit tear fluid for $72 \mathrm{~h}$, with an effect on IOP for $144 \mathrm{~h}$. The same group also incorporated multiple reservoirs into the peripheral region of the CLs for the simultaneous delivery of timolol, bimatoprost, and hyaluronic acid [123]. Ciolino et al. [124,125] obtained a long-lasting release of latanoprost (one month), both in vitro and in a rabbit model, from PLGA spin-coated films that were implanted in the peripheral region of methafilcon CLs. However, as rabbits were not responding to the latanoprost therapy, the device was also tested on glaucomatous monkeys: the results evidenced that the IOP lowering efficacy was as least equal to the daily administration of eye drops. Song et al. [126] engineered multifunctional CLs, which were able to measure IOP, in order detect glaucoma biomarkers and deliver timolol for one month in vitro: an aluminum oxide nanoporous thin film with a central hole was incorporated in PDMS lenses, and served both as a power-free sensor and a drug reservoir with a prolonged release over time.

The management of storage time and conditions is another issue related to drugloaded devices. In order to prevent drug loss during shipping and storage, triggered release systems have been proposed in the last years, and some strategies have been applied to CLs. Inner layer-embedded CLs with a $\mathrm{pH}$-triggered release of betaxolol hydrochloride were obtained by Zhu et al. by incorporating the drug in a cellulose acetate/Eudragit $\mathrm{S} 100 \mathrm{blend}$ film. The drug was detected for $240 \mathrm{~h}$ in the tear fluid of a rabbit model [138]. Lysozyme-triggered degradation of acetylated chitosan was suggested for the release of TM in the presence of the lacrimal fluid enzyme [103]: briefly, nanogels were synthetized by crosslinking polyethyleneimine-coated nanodiamonds with chitosan in the presence of TM, and then incorporated into CLs. The degree of chitosan acetylation controlled the polymer degradation and, therefore, the release profile. A sustained and gradual release was detected for at least $48 \mathrm{~h}$ in vitro. A different strategy was used to obtain daylight-mediated timolol release. The drug molecule was linked to the CL by a photocleavable caged crosslinker (dimethoxy-substituted 2-nitrobenzene caged group) [136]. Bond breakage was triggered by $400-430 \mathrm{~nm}$ light, and therapeutic amounts of timolol were released for $10 \mathrm{~h}$. The estimated relative low fabrication cost would also allow for a daily lens disposal and it would avoid risks of contamination during reloading procedures. A drug release that was triggered by body temperature was obtained while using PNIPAM as a carrier for TM: bicontinuous microemulsion CLs, constituted by continuous aqueous and oily phases, provided a nanoporous structure that was suitable to load a TM-PNIPAM nanogel by centrifuging and soaking [104]. The release time (72 h-30 days) was controlled by selecting the appropriate initial volume of drug loaded, the loading parameters, and the loading medium. in vivo experiments on rabbit models detected TM in the aqueous humor up to seven days, with a significant decrease of IOP within $2 \mathrm{~h}$ from lens application [137].

\subsection{Cataract}

A cataract is defined as the opacification of the natural crystalline lens with a consequent decrease in the quality of vision [140]. It is the leading cause of vision loss in elderly patients, causing visual impairment in about $30 \%$ of the population over 65 years old, but its incidence is also increasing in the younger population due to the exposition of UV radiation, smoke, use of steroids, increased incidence of diabetes and malnutrition [46,141]. Approximately $20 \%$ of cataract surgeries in the western population are performed on diabetic patients [142].

Diabetic crystalline lenses are characterized by an increased level of free radicals and impaired antioxidant capacity, which leads to an increased susceptibility to oxidative stress. Cataract development occurs at an earlier age in presence of diabetes, but an appropriate 
metabolic control can contribute to the lens recovery in young patients [143]. The administration of aldose-reductase inhibitors (ARIs) and antioxidants was also demonstrated to be beneficial in the delay of diabetic cataract in the early stage of the pathology and it could be useful for its prevention in patients at risk. In order to provide drug-eluting CLs for the local treatment of the diabetic eye, the ARI epalrestat was loaded into silicone hydrogels [88]. A biomimetic strategy was applied for the selection of the hydrogel composition. After loading by soaking, a strong affinity between the drug and aminopropyl methacrylamide (APMA)-functionalized hydrogels was observed and epalrestat was released for up to one week in vitro. The device successfully prevented opacification in extracted porcine crystalline lenses under hyperglycemic conditions [88]. Examples of antioxidants-eluting CLs have also been reported. Yigit and Ercal [37] soaked commercial CLs in $n$-acetylcysteine or $n$-acetylcysteine amide solutions and obtained a suitable release in vitro for daily use of the lenses. Varela-Garcia et al. [144] increased the uptake and the released amount of transferulic acid from hydrogels by functionalization with cytosine, a nitrogenous base with high affinity for a variety of drugs. Functionalization was performed by soaking the hydrogels in a cytosine/water/dioxane solution after polymerization.

Cataract surgery currently remains the standard treatment of severe cataractous eyes. The procedure consists in the removal of the damaged lens and a subsequent implant of an IOL. Despite the advances in the technique and the evolution in the different types of IOLs made this procedure one of the most cost-effective in the current healthcare [46], some post-operative complications can still occur and cause patient discomfort and visual impairment, as well as a prolonged recovery time [145]. An inflammatory response due to the physical trauma that is associated to surgery is considered to be physiological and it is generally treated with topical non-steroidal anti-inflammatory drugs (NSAIDs) or corticosteroids. If untreated, persistent inflammation can lead to pseudophakic cystoid macular edema (PCME), uveitis, iritis, glaucoma, and an increase of IOP $[145,146]$. Diabetic patients are at increased risk of developing these diseases. A recent clinical trial by McCafferty et al. [146] on 662 patients evidenced that PCME was the most common complication after cataract surgery. Because of the higher sensitivity of the vascular bed in diabetic patients, approximately $4-12 \%$ of patients affected by diabetes mellitus $[142,147]$ and up to $56 \%$ of patients with diabetic retinopathy [148] are expected to develop PCME after IOL implant. Ocular infection, often linked to endophthalmitis, is another possible adverse condition, and it is mostly caused by bacterial migration from the lid and conjunctiva to the intraocular space. In this case, prevention and treatment involve the use of topical corticosteroids and antibiotics [145]. The migration and proliferation of epithelial cells to the posterior surface of the IOL can also lead to visual impairment after surgery; the phenomenon is known as posterior capsule opacification (PCO), and it is commonly treated by a laser procedure [149]. Postoperative endophthalmitis and early PCO are both reported to develop at a higher incidence rate in diabetic patients [150,151].

The current prophylaxis after cataract surgery consists in the administration of antibiotics and anti-inflammatory drugs (NSAIDs and/or corticosteroids) in the form of eye drops for two to four weeks after IOL implantation. The Food and Drug Administration approved a new intracameral drug-release device (DEXYCU, Icon Bioscience Inc., Newark, CA) in 2018 for the treatment of postoperative inflammation associated to cataract surgery [152]. The device is constituted by an injectable dexamethasone suspension, which is able to guarantee a 21-days long therapeutic level of drug release. The suspension is injected at the end of cataract surgery, forming a surface tension-based sphere positioned aside the IOL and behind the iris. The use of CLs as drug depots for antibiotics and antiinflammatories has been proposed as a less-invasive alternative (Table 2) [21,111]. However, in the case of cataract surgery, postoperative prophylaxis could be more efficiently achieved by use of drug-loaded IOLs (Table 2), in order to overcome the issues that are related to patient compliance and poor drug permeability through the cornea, to which both eye drops administration and drug-eluting CLs are subjected [47]. 
By soaking in antibiotic solutions (i.e., moxifloxacin or gatifloxacin) for $15 \mathrm{~min}$, Lipnitzki et al. [39] obtained a drug-eluting HEMA-MMA IOL that, when implanted into rabbit eyes, exhibited a slower decrease of the drug concentration in the aqueous humor as compared to a single intracameral drug injection performed after surgery. However, the drug could only be detected up to a few hours after implant placement. More recently, Topete et al. [40] reached a minimum of eight-day release period of moxifloxacin, diclofenac, or ketorolac from commercially available hydrophilic IOL material through the optimization of the temperature and time of soaking. In particular, loading at $60^{\circ} \mathrm{C}$ for two weeks allowed for maximizing drug loading and sustaining moxifloxacin or diclofenac release over time. Subsequent in vivo studies on rabbits [41] proved the suitability of moxifloxacinloaded IOLs as delivery devices at therapeutic drug concentrations for at least one week. In order to perform an effective prophylaxis for endophthalmitis after cataract surgery, the simultaneous release of moxifloxacin and ketorolac was then successfully experimented, obtaining the release of the antibiotic and anti-inflammatory drugs for at least 15 days. The presence of both drugs enhanced the release profile [24]. Pimenta et al. also achieved the dual release of NSAIDs and antibiotics (i.e., diclofenac and moxifloxacin) [42]. In this case, loading was sequentially performed in the two drug solutions. The obtained IOLs are expected to be effective in vivo for three weeks.

Li et al. [25] incorporated $\beta$-cyclodextrins into HEMA-MMA hydrogels in order to increase the amount of dexamethasone loaded during the soaking step in the drug solution. A sustained drug release was obtained through the hydrogel modification, but it only lasted a few days.

Supercritical fluid impregnation has also been applied to IOL materials. In 2012, González-Chomón et al. [60] developed an acrylic hydrogel that was based on the addition of 2-butoxyethyl methacrylate (BEM) to HEMA. This hydrogel was foldable even in dry state and therefore implantable through minor corneal incision. An increase in the BEM fraction led to a lower swelling due to the hydrophobic character of this compound and reduced norfloxacin loading by traditional soaking methods. This problem could be solved by supercritical $\mathrm{CO}_{2}$ impregnation that notably increased drug loading in the hydrogels. In the same study, the incorporation of small quantities of acrylamide or methacrylic acid as functional monomers was also tested with positive outcomes on the total amount of drug loaded. Bouledjouidja et al. loaded commercial foldable HEMA-based [26] or rigid MMA-based [92] IOLs with ciprofloxacin or dexamethasone. in vitro drug release was kept for several days by the optimization of the impregnation parameters (i.e., pressure, duration, and presence of a co-solvent). No effect on the dioptric power of the impregnated lenses was detected [95]. Ongkasin et al. recently adopted the same technique for the loading of gatifloxacin [96] into commercially available hydrophobic IOLs. The effect of the parameter optimization on the impregnation yield was evaluated, but no data on the drug release profile were reported.

In other studies, the application of either drug-eluting or drug-barrier coatings onto the IOL surface was attempted. Layer by layer (LbL) deposition was adopted as a drugdepot coating carrying ampicillin [65], and a sustained release was obtained over days. LbL coatings were tested as barriers to the release of diclofenac, moxifloxacin, ketorolac, or chlorhexidine [70], but only diclofenac evidenced a slower release after the modification. Plasma-assisted grafting with HEMA [71] or 2-acrylamido-2-methylpropane sulfonic acid [66] in the presence of moxifloxacin resulted in a 15-day drug release above the therapeutic concentration, which is comparable to the common duration of the prophylactic treatment that is required after surgery. 
Table 2. Therapeutic ophthalmic lenses developed between 2010 and 2020 suitable for the prevention of cataract and pathologies that are associated to cataract surgery.

\begin{tabular}{|c|c|c|c|c|c|}
\hline & Pharmacological Action & Drugs & Lens Type & Backbone Monomers & Ref. \\
\hline \multirow{3}{*}{ 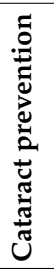 } & Aldose-reductase inhibitor & Epalrestat & CL & Sil-HEMA & [88] \\
\hline & \multirow[t]{2}{*}{ Antioxidant } & Acetylcysteine & $\mathrm{CL}$ & $\begin{array}{c}\text { HEMA-PVP } \\
\text { Sil-DMA-HEMA-PVP } \\
\text { HEMA-MAA }\end{array}$ & [37] \\
\hline & & Transferulic acid & $\mathrm{CL}$ & HEMA-GMA-EGPEM & [144] \\
\hline \multirow{11}{*}{ 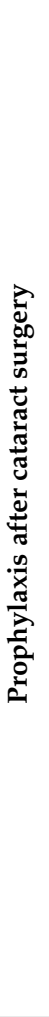 } & \multirow{6}{*}{ Antibiotics } & Norfloxacin & IOL & $\begin{array}{c}\text { HEMA } \\
\text { HEMA-BEM }\end{array}$ & $\begin{array}{l}{[23]} \\
{[60]}\end{array}$ \\
\hline & & Moxifloxacin & IOL & $\begin{array}{c}\text { HEMA-MMA } \\
\text { Silicone hydrogel (N/A) } \\
\text { N/A }\end{array}$ & $\begin{array}{c}{[24,39-42,66,70,71,153]} \\
{[153]} \\
{[118]}\end{array}$ \\
\hline & & Ciprofloxacin & IOL & $\begin{array}{l}\text { HEMA } \\
\text { HEMA-MMA } \\
\text { PolyMMA }\end{array}$ & $\begin{array}{l}{[26]} \\
{[95]} \\
{[92]}\end{array}$ \\
\hline & & Gatifloxacin & IOL & $\begin{array}{l}\text { HEMA-MMA } \\
\text { BMA-MMA }\end{array}$ & $\begin{array}{l}{[39]} \\
{[96]}\end{array}$ \\
\hline & & Ampicillin & IOL & PolyMMA & [65] \\
\hline & & Levofloxacin & IOL & $\begin{array}{c}\text { HEMA-MMA } \\
\text { Silicone hydrogel (N/A) }\end{array}$ & $\begin{array}{l}{[153]} \\
{[153]}\end{array}$ \\
\hline & \multirow[b]{2}{*}{ NSAIDs } & Diclofenac & IOL & $\begin{array}{c}\text { HEMA-MMA } \\
\text { Silicone hydrogel (N/A) }\end{array}$ & $\begin{array}{c}{[24,40,42,70,153]} \\
{[153]}\end{array}$ \\
\hline & & Ketorolac & IOL & $\begin{array}{c}\text { HEMA-MMA } \\
\text { Silicone hydrogel (N/A) }\end{array}$ & $\begin{array}{c}{[24,40,70,153]} \\
{[153]}\end{array}$ \\
\hline & \multirow[t]{2}{*}{$\begin{array}{c}\text { Steroidal anti-inflammatory } \\
\text { drugs }\end{array}$} & Dexamethasone & IOL & $\begin{array}{c}\text { HEMA } \\
\text { HEMA-MMA } \\
\text { PolyMMA }\end{array}$ & $\begin{array}{c}{[26,95]} \\
{[25,95]} \\
{[92]}\end{array}$ \\
\hline & & Triamcinolone acetonide & IOL & PEA-PEMA & [119] \\
\hline & Immunosuppressant & Cyclosporine A & IOL & PEA-PEMA & [119] \\
\hline \multirow{7}{*}{ 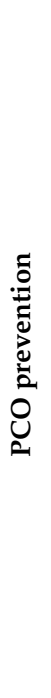 } & \multirow{7}{*}{$\begin{array}{l}\text { Anti-proliferation or } \\
\text { apoptosis-inducing drugs }\end{array}$} & $\begin{array}{l}\text { Celecoxib } \\
\text { Erufosine }\end{array}$ & $\begin{array}{l}\text { IOL } \\
\text { IOL }\end{array}$ & $\begin{array}{l}\text { Hydrophilic acrylic (N/A) } \\
\text { Hydrophilic acrylic (N/A) }\end{array}$ & {$[32]$} \\
\hline & & Erlotinib & IOL & $\begin{array}{l}\text { Hydrophilic acrylic (N/A) } \\
\text { Hydrophobic acrylic (N/A) }\end{array}$ & [34] \\
\hline & & Gefitinib & IOL & $\begin{array}{l}\text { Hydrophilic acrylic (N/A) } \\
\text { Hydrophobic acrylic (N/A) }\end{array}$ & [35] \\
\hline & & Methotrexate & IOL & $\begin{array}{l}\text { Hydrophilic acrylic (N/A) } \\
\text { Hydrophobic acrylic (N/A) }\end{array}$ & $\begin{array}{l}{[36,64]} \\
{[36,97]}\end{array}$ \\
\hline & & $\begin{array}{l}\text { Rapamycin } \\
\text { Y27632 }\end{array}$ & $\begin{array}{l}\text { IOL } \\
\text { IOL }\end{array}$ & $\begin{array}{l}\text { PolyMMA } \\
\text { PEA-PEMA }\end{array}$ & $\begin{array}{l}{[72]} \\
{[73]}\end{array}$ \\
\hline & & Doxorubicin & IOL & $\begin{array}{l}\text { Hydrophobic acrylic (N/A) } \\
\text { Hydrophobic polyester }\end{array}$ & $\begin{array}{c}{[74]} \\
{[74,105]}\end{array}$ \\
\hline & & $\begin{array}{c}\text { Indocyanine green } \\
\text { MMPI } \\
\text { 5-fluorouracil }\end{array}$ & $\begin{array}{l}\text { IOL } \\
\text { IOL } \\
\text { IOL }\end{array}$ & $\begin{array}{c}\text { N/A } \\
\text { PDMS } \\
\text { PolyMMA }\end{array}$ & $\begin{array}{c}{[77]} \\
{[154]} \\
{[106]}\end{array}$ \\
\hline
\end{tabular}

The incorporation of drug reservoirs in the implanted IOL was first suggested between 2006 and 2008 [27,117]. More recently, antibiotics, like norfloxacin [23] and levofloxacin [118], were loaded into polymeric reservoirs that were attached to the IOL's haptics or to the lens edges, respectively, and released a clinically relevant drug dosage 
for at least 15 days. Two reservoirs containing different drugs could be paired in order to obtain a synergic effect: Eperon et al. [119] combined the release of triamcinolone acetonide and cyclosporine A to increase the therapeutic effect of the IOL. The implanted system reduced inflammation for more than three months in rabbits.

The incidence rate of PCO can be lowered through an appropriate design of the implanted IOLs. Several studies focused on the influence of the lens material [155], edge squareness, and surface modifications $[156,157]$ in order to inhibit cell adhesion and proliferation on the device. Square edges, in particular, inhibit the migration of epithelial cells to the optic part of the IOL, thus preventing the pathology [158]. Drug-eluting IOLs have been recently proposed to pharmacologically hinder PCO. Celecoxib [32], erufosine [33], erlotinib [34], gefitinib [35], and methotrexate [36] were loaded with this purpose into IOLs by soaking in drug solutions. Despite the short-term release that is achieved with most of the investigated systems, a long-term effect on the proliferation of epithelial cells was registered with ex vivo canine models or human capsular bag models, suggesting the suitability of the method.

Drug-releasing PLGA coatings were designed for the release of rapamycin [72], methotrexate (MTX) [64] or Y27632, an inhibitor of Rho-associated kinase [73]: in the case of rapamycin, the coating was applied to the edge of the IOL optics, while MTX and Y27632-enriched coatings were applied to the optic part without affecting transparency. Rapamycin-loaded IOLs resulted in being more effective in treating PCO in rabbits as compared to the administration of capsular irrigation during surgery or eye drops, and the drug was detected in the aqueous humor for weeks. MTX-loaded IOLs showed promising results in a human capsular bag model: the drug was released for 14 days, but a high initial burst release was observed. Y27632 was released in vitro for only one day. Despite this, a significantly lower PCO incidence was registered in rabbits after implantation, in line with previous studies regarding the long-term effect of short-term treatment for PCO.

Zhang et al. [77] obtained the laser-triggered release of indocyanine green, a photosensitizer, from commercially available IOLs by spray-coating the active agent on the lens surface and, subsequently, controlling the release with a sealing layer of PLGA. However, low transmittance, related to both the presence of indocyanine green and to PLGA degradation, remained an issue over several weeks after immersion in PBS, affecting the suitability of the system for the intended ocular application.

Chitosan nanoparticles that were loaded with doxorubicin $[74,105]$ or 5-fluorouracil [106], applied to the IOL surface by LbL deposition or ion-beam functionalization, also sustained drug release over days and reduced PCO incidence in rabbits.

Different matrix metalloproteinases inhibitors (MMPI) were embedded in a PDMS lens mixture prior to curing or by soaking the PDMS discs in a drug-ethanol solution for four days. For some of the obtained systems, drug release was sustained for up to five months and a significant reduction in the human epithelial cell migration rate was observed after in vitro exposure to the drug-eluting lenses [154].

Supercritical fluid technology was also suggested to implement methotrexate releasing acrylic IOLs. The drug was eluted in vitro for more than 80 days. In this case, the device did not cause any significant difference in the time that is required to reach cell confluence in a human capsular bag model, but fibrosis was reduced by inhibiting cell transformation from epithelial to mesenchymal phenotype, which has a major role in PCO formation [97].

\subsection{Corneal Diseases}

Keratoconjunctivitis sicca, or dry eye syndrome, is a common condition of the anterior segment of the eye, which can be associated to discomfort, burning sensation, external body sensation, ocular pain, light sensitivity, and intermittent blurred vision [159]. The presence of a normal tear film is fundamental for corneal health and immune protection [160] and the prevention of corneal injuries. Ocular lubrication can be compromised by reduced tear production and/or instability of the tear film, leading to a rapid evaporation from the eye surface. Various causes have been identified, including environmental factors (low ambient 
humidity, excessive wind or dust, temperature extremes, air conditioning), ageing, allergies, a prolonged computer use, metabolic conditions and nutritional deficiencies, contact lens use, and the prolonged administration of systemic or topical drugs (e.g., antiglaucoma medications or preservative-containing eye drops) [161]. Patients that are affected by neuropathic disorders, Sjögren's syndrome, lupus, blepharitis, or congenital abnormalities of the lid are more prone to developing dry eye symptoms [162].

Other common corneal diseases are keratitis, a corneal inflammation that is usually treated by topical or systemic administration of antibiotics, biocides, antifungals, or antivirals, depending on the type of infection [163], and exposure keratopathy, often caused by an inadequate eyelid closure and treated by the use of lubricating drops or by surgical procedure [164]. Bullous keratopathy and Fuch's dystrophy, on the contrary, are caused by an impairment of the corneal endothelium which loses the ability to drain fluid out of the cornea. Hypertonic topical solutions are usually prescribed to reduce the resulting corneal edema [165], and the concomitant wearing of bandage contact lenses is suggested to increase the residence time of eyedrops on the corneal surface $[166,167]$. Inherited corneal dystrophies, such as keratoconus, lattice dystrophy, and map-dot-fingerprint dystrophy, can lead to a major visual impairment at their advanced stage [168].

Although often overlooked, complications in the anterior segment of the eye are also common in diabetic patients [169]. It is estimated that diabetic keratopathy affects approximately $47-64 \%$ of diabetic patients and, if not treated, it can lead to major visual impairment [170]. Keratopathy is associated with an increased risk of corneal epithelial defects, recurrent erosions, delayed epithelial wound healing, tear film alteration, edema, and neurotropic corneal ulcers $[160,169,170]$. In severe cases, hyperglycemia and microvascular damage cause corneal neurotrophic lesions and a progressive decrease in corneal nerve fiber density, which lead to a loss of sensitivity, an impairment of the epithelial healing process, and a lack of feedback control over tear secretion [169,171]. An abnormal regulation of the healing mechanism can cause corneal opacity and blindness [172]. Despite the suggested causality between peripheral neuropathy and diabetic keratopathy, direct alterations in the corneal epithelium were also observed in less severe conditions, without signs of neuropathy [160]. In the early stage of the pathology, diabetic patients frequently experience dry eye symptoms [171]. Hyperglycemia, in fact, can cause a microvascular damage to the lacrimal gland, also contributing to the low tear secretion [169]. Alterations in the tear film were also associated to the presence of inflammation, oxidative stress, and the accumulation of advanced glycation end products (AGEs) in the lacrimal gland [160]. Tear film changes, such as a reduced lipid layer quality and film stability, were also registered in diabetics [173].

The current topical treatment of the dry cornea pursues the objective of maintaining a lubricated ocular surface and an intact epithelium through tears replacement [174]. Artificial tears are helpful in maintaining a healthy ocular surface and clear vision [169]. However, they have a low residence time $(5 \mathrm{~min}$.) and need to be administered more than nine times a day, in most serious cases of dry eye $[175,176]$. CLs with incorporated moisturizing macromolecules (Table 3) constitute a strategy for increasing the patient comfort and prevent dry-eye symptoms that are associated to the continuous CL wear. Moreover, their use can avoid periods of blurred vision being encountered after the administration of lubricating eye drops. Several examples of daily disposable lenses with immobilized or free moisturizing agents are already available on the market, such as Focus Dailies with AquaRelease (Alcon), Dailies AquaComfort Plus (Alcon \& Ciba Vision), 1-Day Acuvue Moist (Johnson \& Johnson), and Fusion 1 day (Safilens). The release of comfort agents, as compared to immobilization onto the CLs, presents the advantage of distributing the effect on the ocular surface even away from the lens and increasing the agent effectiveness [81]. Research has been focused on the optimization of a sustained release over time of such macromolecules. Several examples have been reported, such as the incorporation of polyvinyl alcohol (PVA), polyvinylpyrrolidone (PVP), or hyaluronic acid (HA), widely used in artificial tears, into soft CLs for the relief of dry eye symptoms [175]. More recently, 
Maulvi et al. investigated different loading methods for HA on CLs: soaking, direct entrapment during polymerization, and a HEMA-HA ring reservoir. Co-polymerization with HA allowed a sustained delivery for 15 days in rabbit eyes [176], while a nine-day release was obtained from the ring-CLs system [177]. For the same purpose, and through molecular imprinting on silicone hydrogel CLs, White et al. [81] managed to design the release of hydroxypropyl methylcellulose (HPMC), a re-wetting agent, up to 60 days in dynamic release conditions. The same strategy was applied by the group in order to reach the simultaneous delivery of both re-wetting and anti-inflammatory agents (i.e., trehalose, HPMC, prednisolone, and ibuprofen) [178], which, even if not specified by the authors, could be interesting to address the multiple complications of the diabetic cornea. Acrylic acid and 4-vinylphenol were selected as functional monomers, and the molecules were released for several hours in vitro. It is worth considering that, in several pathological eye conditions, as in the case of dry eye, the tear $\mathrm{pH}$ is also affected. Based on this, Kim et al. [179] suggested a pH-triggered release of HPMC from smart HEMA-PVP or HEMA-PNIPAM CLs. HPMC was loaded by soaking, and a release over hours was observed in cyclic $\mathrm{pH}$ conditions. Another approach is to directly address the improvement of the tear lipid layer quality, whose instability (that is commonly observed in diabetic dry eye) causes a rapid evaporation and decreased lubrication. With this aim, Pitt et al. $[180,181]$ engineered the daily release of phospholipids from commercial silicon hydrogel CLs through in vitro studies. The loading of phospholipids was performed by rapid soaking (30-120 s) in a n-propanol solution. The optical transmission and wettability of the lens were not affected by the process. The optimization of the loading parameters (i.e., loading solution concentration, loading time) subsequently allowed achieving a sustained release for 30 days from reusable CLs in vitro [182]. The use of osmoprotectants could also contribute to the reduction of hypertonic stress damage, as dry eye syndrome in diabetic patients is accompanied by hyperosmolarity of the tear film [183]. A step in this direction is represented by the study of Hsu et al. [184], who loaded betaine, an osmoprotectant, or dexpanthenol, a moisturizing agent, into silicon-hydrogel CLs. A pre-soaking in a vitamin E solution was performed prior to soaking in betaine or dexpanthenol solutions, in order to increase the in vitro release duration time from approximately $15 \mathrm{~min}$. to $12 \mathrm{~h}$.

Although the administration of lubricating agents can contribute to symptom relief and the prevention of corneal injuries, a pharmacological treatment is often prescribed in pathological conditions (Table 3). The use of topical antibiotics and anti-inflammatory drugs is suggested to alleviate surface inflammation and promote the re-epithelialization of the cornea $[169,174]$. The most widely used anti-inflammatory topical drugs for dryeye syndrome are corticosteroids, NSAIDs, and cyclosporine A [185]. In recent years, several examples of the mentioned drugs have been incorporated into CLs using many different techniques, and the obtained results have been extensively discussed in previous review papers $[21,111,186]$. Therapeutic CLs for the treatment of keratitis have also been widely reported in literature reviews $[187,188]$, with promising results for the delivery of biocides [189,190], antifungals [189,191-194], and antiviral drugs [195,196].

In 2014, Jacob et al. proposed a CL-assisted surgical treatment of keratoconus [197]. The loss of structural stability associated to the pathology results in a progressive corneal thinning, deformation, and impaired vision. The structural support of hard contact lenses is the first-line treatment, but their use does not alter the progression of the condition. The photo-induced collagen polymerization emerged in the last decade as an effective method for stopping the progression of keratoconus and increase the corneal stiffness [198]. In order to perform the procedure, riboflavin is used as a photosensitizer for collagen. By soaking a commercial UV barrier-free CL into a riboflavin solution, it was possible to obtain a riboflavin reservoir for corneal crosslinking. The riboflavin-CL system also artificially increased the thickness of the lens-corneal layer, which results in a UV protective shield for the corneal endothelium. Pilot studies were conducted with promising results [199].

Overall, the controlled use of topical corticosteroids or NSAIDs can be beneficial in inflammatory corneal diseases. However, it must be stressed that the prolonged use of 
steroidal drugs is associated to an increased IOP and a higher incidence of cataract, for which certain categories, such as diabetic patients, are already considered to be at risk. On the other hand, NSAIDs can lead to a decrease in corneal sensitivity and the dissolution of corneal epithelium [185]. Even in absence of adverse events, their application remains limited to the treatment of dry eye-related symptoms. Promising new strategies have been suggested for a wider approach to the anterior segment pathologies, addressing, for example, neurotrophic keratitis, persistent epithelial defects, diabetic keratopathy, and diabetic neuropathy, such as the use of topical insulin, naltrexone, ARIs, substance P, and different growth factors $[160,169,170,174,200]$.

Naltrexone (NTX) is an opioid antagonist, whose systemic or topical administration proved to block the negative effect of opioid growth factors, which are excessively present in diabetic patients, on cell proliferation and tissue growth. The use of naltrexone eye drops resulted in an accelerated corneal wound healing and the restoration of corneal sensitivity in many animal models, and it is considered to be a promising treatment of diabetic keratopathy $[160,174]$. Alvarez-Rivera et al. recently developed a NTX-releasing CL [87] while using molecular imprinted HEMA hydrogels. A bioinspired approach was applied for the selection of functional monomers and the incorporation of acrylic acid was found to increase the amount of drug that was loaded into the hydrogel. NTX was released from imprinted CLs in a sustained fashion for at least two days in both sink and dynamic conditions in vitro, and the attained drug concentration in a bovine cornea model was comparable to that obtained with administration of a drug solution $(\mathrm{t}=6 \mathrm{~h}$ after administration).

Several growth factors (i.e., epidermal growth factor, basic fibroblast growth factor, transforming growth factor-beta, platelet derived growth factor, insulin-like growth factor, and vascular endothelial growth factor) have a role in the control of corneal epithelial cells proliferation, migration, and apoptosis, and they are fundamental in the corneal healing process [203]. The topical administration of growth factors proved to be beneficial in the treatment of persistent epithelial defects, neurotrophic keratitis, and for the recovery of corneal epithelium after surgery [200]. Altered levels of growth factors have been also registered in diabetic tissues, and the restoration of their physiological expression has been tested with promising results in clinical trials [160]. The release of growth factors from CLs was also investigated, aiming to increase the bioavailability and residence time of such therapeutic agents. In 2010, Schultz and Morck [43] obtained vasurfilcon A CLs (that are composed of methyl methacrylate, vinyl pyrrolidone, and other methacrylates) that are able to release epidermal growth factor (EGF): after loading in a EGF solution for $7 \mathrm{~h}$, EGF was released for $4 \mathrm{~h}$ in vitro. Despite the short duration of release, a therapeutic effect of the obtained device was observed on rabbit eyes with induced corneal abrasion as compared to untreated eyes. The same EGF loading procedure resulted unsuitable for silicone-based CLs. Later, the same group performed preliminary clinical tests by applying the EGF-loaded CLs onto nine patients with corneal epithelial defects not responding to conventional therapies [202]. Complete recovery was achieved in seven patients after wearing the device for 4-13 days. A previously developed significant ocular inflammation was reported in the two unsolved cases. No adverse events were registered, but wider randomized and controlled clinical trials are still requested in order to assess the efficacy of the device and, in particular, its suitability for the treatment of metabolic-induced corneal defects. Pursuing the same objective, Sandri et al. [203] loaded platelet derived growth factors (PDGF) onto various commercial CLs. In order to perform the loading, two solutions of platelet lysate and chondroitin sulfate were poured into the concavity of the CLs and then kept for $24 \mathrm{~h}$ at $25^{\circ} \mathrm{C}$. Due to its electrostatic interaction with positively-charged growth factors, the presence of chondroitin sulfate stabilized and reduced degradation in PDGF. After loading, PDGF were gradually released over $6 \mathrm{~h}$ from PureVision ${ }^{\circledR}$ silicone lenses in vitro, while promising results were obtained by preliminary in vitro wound healing assay. 
Table 3. Therapeutic ophthalmic lenses developed between 2010 and 2020 suitable for the prevention and treatment of corneal diseases.

\begin{tabular}{|c|c|c|c|c|}
\hline Pharmacological Action & Drugs/Agents & Lens Type & Backbone Monomers & Ref. \\
\hline \multirow{5}{*}{$\begin{array}{l}\text { Lubricating agents, } \\
\text { moisturizing agents }\end{array}$} & HA & $\mathrm{CL}$ & $\begin{array}{l}\text { HEMA-MAA } \\
\text { Modified PVA }\end{array}$ & $\begin{array}{c}{[176,177]} \\
{[175]}\end{array}$ \\
\hline & HPMC & CL & $\begin{array}{c}\text { HEMA(-PVP/pNIPAAm) } \\
\text { Sil-DMA } \\
\text { Sil-DMA-PDMS }\end{array}$ & $\begin{array}{c}{[179]} \\
{[81]} \\
{[178]}\end{array}$ \\
\hline & Phospholipids & $\mathrm{CL}$ & Silicone hydrogel (N/A) & [180-182] \\
\hline & Dexpanthenol & CL & $\begin{array}{c}\text { Sil-DMA-HEMA-PVP } \\
\text { Sil-DMA-HEMA-PVP-PDMS }\end{array}$ & [184] \\
\hline & Trehalose & $\mathrm{CL}$ & Sil-DMA-PDMS & [178] \\
\hline Osmoprotectant & Betaine & CL & $\begin{array}{c}\text { Sil-DMA-HEMA-PVP } \\
\text { Sil-DMA-HEMA-PVP-PDMS }\end{array}$ & [184] \\
\hline $\begin{array}{c}\text { Antibiotics and } \\
\text { anti-inflammatory drugs }\end{array}$ & $\begin{array}{c}\text { Corticosteroids, } \\
\text { NSAIDs, cyclosporine } \\
\text { A, antibiotics }\end{array}$ & CL & Various compositions & {$[21,178]$} \\
\hline \multirow{3}{*}{ Keratitis medication } & Biocides & CL & $\begin{array}{l}\text { HEMA-MAA-PVP } \\
\text { Poly- } \varepsilon-l y s i n e\end{array}$ & $\begin{array}{l}{[189]} \\
{[190]}\end{array}$ \\
\hline & Antifungals & CL & $\begin{array}{c}\text { Silicone hydrogel (N/A) } \\
\text { Poly- } \varepsilon \text {-lysine } \\
\text { HEMA-PC } \\
\text { HEMA-MAA } \\
\text { HEMA-MAA-PVP } \\
\text { Sil-DMA-HEMA-PVP } \\
\text { Quaternized chitosan + graphene oxide }\end{array}$ & $\begin{array}{c}{[191,194]} \\
{[193]} \\
{[194]} \\
{[194]} \\
{[189,194]} \\
{[194]} \\
{[192]}\end{array}$ \\
\hline & Antivirals & $\mathrm{CL}$ & HEMA-MAA & {$[195,196]$} \\
\hline Collagen photosensitizer & Riboflavin & CL & $\begin{array}{l}\text { HEMA-PVP } \\
\text { Sil-DMA } \\
\text { PVP-MMA }\end{array}$ & $\begin{array}{c}{[197,199,201]} \\
{[201]} \\
{[201]}\end{array}$ \\
\hline Opioid antagonist & Naltrexone & CL & HEMA & [87] \\
\hline \multirow[b]{2}{*}{ Growth factor } & EGF & CL & $\begin{array}{l}\text { HEMA-PVP } \\
\text { Sil-DMA } \\
\text { PVP-MMA }\end{array}$ & $\begin{array}{c}{[202]} \\
{[43]} \\
{[43]}\end{array}$ \\
\hline & PDGF & CL & $\begin{array}{c}\text { Modified PVA } \\
\text { Sil-PVP } \\
\text { Sil-DMA } \\
\text { Sil-DMA-HEMA-PVP-PDMS }\end{array}$ & [203] \\
\hline Aldose reductase inhibitor & Epalrestat & CL & Sil-HEMA & {$[88]$} \\
\hline Antioxidant & Lactoferrin & CL & Silicone hydrogels (N/A) & {$[44,45]$} \\
\hline
\end{tabular}

The administration of ARIs proved to successfully inhibit the polyol pathway, being responsible for several diabetic eye complications, including dry eye syndrome. Both oral and topical treatment with ARIs improved tear production and corneal sensitivity, reduced nerve damage, and promoted corneal epithelial regeneration in diabetic patients $[169,185,204]$. Therefore, the previously mentioned incorporation of epalrestat into silicone CLs [88] could perform a multiple action for a wider control of diabetic-related ocular pathologies, including keratopathy, neuropathy, and cataract prevention. Similarly, the administration of topical antioxidants can not only be beneficial for the symptoms of 
retinal diseases, glaucoma, and diabetic cataract, but also for keratopathy and dry-eye syndrome $[144,205]$.

Tissues in the anterior segment of the eye are particularly at risk for the development of atmospheric and light-induced oxidative stress. In physiological conditions, several defense mechanisms are active in preventing damage, such as the presence of antioxidant agents in the tear fluid and in the aqueous humor. Ascorbic acid, lactoferrin (LF), uric acid, and cysteine [205], for example, are present in high concentration in the tear fluid, but, in the case of decreased tear production or tear film instability, the protection of the anterior cornea may become less effective. Increased levels of oxidative and glycoxidative stress have been observed in the cornea of diabetic and keratoconus patients [45,206]. In order to counteract the oxidative stress effects, LF has been loaded into various commercial CLs by soaking in a apolactoferrin solution [44,45]. Cell viability was improved after LF release, in an epithelial cell model with induced oxidative stress. However, the maximum LF release was reached in only $1 \mathrm{~h}$. Different loading strategies could help improve the release profile over time and, consequently, the clinical efficacy of the device in the treatment of corneal pathologies.

\subsection{Posterior Segment Diseases}

Macular degeneration, diabetic retinopathy, and diabetic macular edema are the most common vision-impairing diseases of the back of the eye [207]. AMD is the leading cause of elderly blindness in the United States, affecting 9.2\% of individuals over 50 years old $[208,209]$. The pathology can be manifested under two forms, namely dry and wet AMD. Although dry AMD is more frequent, with an incidence above $85 \%$ in AMD patients, wet AMD is responsible for $90 \%$ of severe vision loss cases [209]. In the case of dry AMD, a thinning of the retinal pigment epithelium is observed, leading to blurred central vision [209]. Wet AMD is associated to retinal hemorrhage and fibrovascular tissue formation, due to an abnormal neovascularization, with the accumulation of subretinal or intraretinal fluid [210]. Cardiovascular diseases, which are linked to a higher hydrostatic pressure in the eye vessels, constitute a risk factor for the development of wet AMD [208], as well as smoking, obesity, and hereditary factors.

Most of the pathologies of the back of the eye in diabetic patients, such as DR and DME, are caused by the long term and chronic progression of microvascular damage in the retina associated with persistent hyperglycemia [211]. In its non-proliferative stage, DR is associated to an abnormal vessel permeability or the presence of microaneurysms in the capillaries. Consequently, the leaking of fluid and its accumulation in the surrounding tissue can lead to the progression of macular edema [6] and, if the subsequent swelling or thickening of the retina occurs in the fovea, DME can significantly affect vision [211]. DME can be diagnosed at any stage of DR, and its incidence increases with the progression of DR and with the duration of diabetes. Poorly controlled blood pressure, smoking, a high cholesterol level, and a reduced kidney function are also considered to be risk factors for the development of the pathology [211]. At its proliferative stage, DR can be directly related to vision impairment. In fact, neovascularization is promoted on the retinal surface due to the occlusion of capillaries, but the fragility of the newly formed capillaries leads to frequent hemorrhages. The accumulation of blood in the vitreous affects vision, while the formation of fibrotic tissue can lead to traction retinal detachment and permanent blindness $[6,211]$. Approximately one-third of diabetic patients are expected to develop $\mathrm{DR}$, and one-tenth of these are associated to sight-threatening states [212]. Even if strict blood glucose and blood pressure control have a protective effect on the development and progression of retinopathy, they are not associated to the complete elimination of the threat.

In the past, the standard of care for proliferative DR and wet AMD was laser photocoagulation of the retinal capillaries. However, laser treatment is a destructive intervention that does not address the cause of the pathology $[6,211]$. The procedure is considered effective, but it is associated to side effects. For this reason, the pharmacological treatment of AMD, DR, and DME gained interest in the last decade. Alternative methods to eye drop 
administration have been explored for the delivery of drugs to the back of the eye due to the low penetration of many common ophthalmic drugs through the corneal epithelium and to the important drug loss caused by lacrimation [18]. The presence of the aqueous humor, the crystalline lens and the vitreous humor constitute additional barriers for drug delivery to the retina through the corneal route. An alternative path is constituted by the conjunctival-scleral route, despite the massive drug loss caused by drug absorption into the systemic circulation $[10,20]$.

Intravitreal injections are adopted for many retinal diseases, although more invasive for the patient and associated to side effects, because they allow to deliver high doses of drug to the posterior segment of the eye [18]. Intravitreal corticosteroids, for example, have been successfully used to treat DR and DME. The intraocular administration of vascular endothelial growth factor inhibitors (anti-VEGF) or the delivery of neuroprotective agents is commonly adopted for the treatment of AMD, DR, and DME, which could be associated to laser treatment for a synergistic effect $[207,212]$. Monthly treatments are usually necessary due to the short half-life of drugs administered by intravitreal injections [19]. Peri-ocular administration, such as sub-tenon and subconjunctival injections, are associated to a minor risk for the patient as compared to intravitreal administration, but also to a lower efficacy [19]. In order to increase the patient comfort and decrease the risk of adverse events that are associated to frequent intravitreal injections, intravitreal implants are designed to sustain drug delivery to the posterior segment of the eye for several months [48]. By using these devices, a higher control of drug concentration in the eye over time is possible, thus avoiding the initial peak that is associated to the traditional injections.

The development of CLs and IOLs as drug depots for the delivery to the posterior segment is still at its initial stage, although some examples were reported in recent literature (Table 4). Despite the advantage of constituting a non-invasive drug-delivery strategy, drug permeability through the ocular barriers is the main issue that is associated to the use of therapeutic lenses for the back of the eye. Schultz et al. [31] investigated the concentration of two small-molecule drugs (prednisolone and beclomethasone) and one larger molecule (ranibizumab) in the ocular tissues of rabbits after cyclic wearing of drug-eluting CLs. Traces of all drugs were detected in the posterior segment, although not in the vitreous, which suggests a drug delivery pathway via the local vasculature. This hypothesis was supported by the study of Ross et al. [120], who encapsulated a dexamethasone-eluting PLGA ring into a CL: the device sustained drug release for one week in vitro, and it reached therapeutic drug levels in the retina in vivo. In fact, the drug concentration in the choroid and retina was significantly higher than in the vitreous of a rabbit model. The obtained retinal drug concentration resulted in being 200 times higher as compared to the effect of repeated administration of eye drops, and successfully inhibited retinal induced vascular leakage, thus proving the potential of therapeutic CLs for drug delivery to the posterior segment of the eye. Sharma et al. [108] also designed lidocaine-eluting PLGA nanoparticles, which were embedded in a collagen membrane that was attached to the CL, for drug delivery to the retina; in this case, however, in vivo studies were not conducted and the suitability of the system for the addressed purpose requires further investigation. A different approach was recently followed by Christopher and Chauhan [213], who proposed the design of CLs to perform iontophoresis. Iontophoresis is a promising technique in ophthalmology for the delivery of charged therapeutic molecules through the ocular barriers while using electromotive forces, but the currently available set-up is composed by two electrodes, one placed on the eye and the other on the ear or forehead. In contrast, the set-up of Christopher and Chauhan contained both of the electrodes into the CL, being less invasive for the patient. This device allowed the delivery of nile blue and fluorescein, selected as model molecules and loaded into the lenses by soaking, to the posterior segment of the eye ex vivo, paving the way for future in vivo experiments on drug delivery to the retina. 
Table 4. Therapeutic ophthalmic lenses developed between 2010 and 2020 potentially suitable for the treatment of the back of the eye.

\begin{tabular}{|c|c|c|c|c|}
\hline Pharmacological Action & Drugs/Molecules & Lens Type & Backbone Monomers & Ref. \\
\hline Steroidal & Prednisolone, beclomethasone & $\mathrm{CL}$ & PVP-MMA & [31] \\
\hline anti-inflammatory drugs & Dexamethasone & CL & HEMA-MAA & [120] \\
\hline Anesthetic & Lidocaine & $\mathrm{CL}$ & $\mathrm{N} / \mathrm{A}$ & [108] \\
\hline Anti-VEGF & Ranibizumab & $\mathrm{CL}$ & PVP-MMA & [31] \\
\hline- & $\begin{array}{l}\text { Nile blue, fluorescein } \\
\text { (iontophoresis) }\end{array}$ & CL & Sil-DMA-HEMA-PVP-PDMS & [213] \\
\hline Immunosuppressant & Cyclosporine A & IOL & PEA-PEMA & [119] \\
\hline
\end{tabular}

If the use of CLs for drug delivery to the back of the eye is still in the initial stage of investigation, then much less studies addressed the use of IOLs for the same delivery purpose. IOLs may offer the intrinsic advantage of directly delivering the drug into the aqueous humor, but their ability to deliver therapeutic drug levels to the vitreous and to the retina is still in need of proper investigation. Interestingly, a bevacizumab-eluting refillable implant [214], in order to be positioned in the peripheral lens capsule during cataract surgery, was designed for the treatment of age-related macular degeneration, thus suggesting the possibility of treating diseases of the back of the eye with drug delivery from the lens capsule and, consequently, also from IOLs. A promising result in this direction was obtained in a previously mentioned study by Eperon et al. [119] while using a rabbit model. Even if the target of the study was the treatment of uveitis with cyclosporine A and triamcinolone acetonide (loaded into drug-eluting reservoirs that are positioned on the IOL haptics), amounts of cyclosporine A were also detected in the retina at day 79 after surgery. This result encourages further investigation involving different therapeutics and drug loading methods. Reservoirs seem to be a very promising strategy, as the they can sustain drug release for several months; in particular, the implementation of IOL-reservoir systems addressed to the treatment of the back of the eye may potentially substitute invasive intravitreal injections for up to one year after surgery, in the case of cataract patients that are affected by pre-existing retinal diseases.

\section{Concluding Remarks and Future Perspectives}

The increasing incidence of age-related eye diseases, as well as the increasing public awareness on ocular conditions in the developed countries, determined an increase in the number of ophthalmology patients and the need for more effective and patient-friendly solutions for drug delivery to the eye. The use of drug-eluting ophthalmic lenses for the prevention and treatment of ocular pathologies, such as glaucoma, cataract, corneal, and retinal diseases, was described in this review.

Several examples of therapeutic CLs and IOLs have been developed in the last decade with promising results. The use of drug-loaded CLs can substitute the topical application of eye drops increasing the drug residence time on the cornea, the drug bioavailability, and the patient compliance. Therapeutic IOLs, which are directly implanted in the anterior chamber, are expected to perform an efficient prophylaxis for post-surgical inflammation and infection or temporarily substitute intraocular injections in case of chronic diseases.

Many examples of therapeutic CLs for the treatment of glaucoma are described in the literature. Several strategies were followed in order to improve drug loading: optimized soaking, the incorporation of functional molecules, coating, molecular imprinting, supercritical impregnation, incorporation of nanocarriers, and reservoir attachment. A prolonged release over days was obtained even by soaking in a drug solution, which constitutes the easiest drug loading method. By the incorporation of drug eluting reservoirs, 
drug release was extended over weeks. Despite the wide research on the topic, only a few examples of in vivo tests on rabbits, dogs, and monkeys were reported, with a lack of preclinical and clinical tests on glaucoma patients, which are indispensable for the future commercial application of the designed devices.

The use of CLs that are loaded with aldose-reductase inhibitors or antioxidants for the prevention of cataract in diabetic patients, especially in the young population, demonstrated, in in vitro studies, to be a promising approach. In the case of impaired vision and the necessity of surgical intervention, the use of therapeutic IOLs, to combine cataract surgery and the subsequent prophylaxis, has been suggested. The possibility of a dual loading of both antibiotics and anti-inflammatory drugs on IOLs constitutes an interesting solution for addressing both post-surgical infection and inflammation. Drug release for 15 days or longer can be obtained with various drugs, thus confirming the suitability of double loaded IOLs for the substitution of the current eye drops prophylaxis, usually administered for two weeks after surgery. Examples of drug eluting IOLs for the prevention of PCO were also reported and, interestingly, long-term effects were observed in rabbits, even in the case of short-term drug release. As previously stated for drug-eluting CLs, extended in vivo tests and subsequent pre-clinical tests are also missing for drug-eluting IOLs, despite the promising results that were obtained in rabbit models.

Keratopathies, which are usually associated to corneal epithelial defects, delayed corneal epithelial healing, tear film instability, and dry eye syndrome, can be caused by several factors, including environmental agents, inherited pathologies, ageing, diabetes, and the use of systemic or topical medications. The first-line treatment is based on the use of artificial tears to maintain a lubricated ocular surface, but a few examples of CLs releasing moisturizing agents are already present on the market. The current research is focused on the optimization of the release profiles of those agents, alone or in association with drugs for pathological conditions. In this latter case, the administration of eye drops is the standard of care, but many therapeutic CLs eluting corticosteroids and NSAIDs were reported in literature. More recently, specific drugs addressed to the treatment of keratopathy were suggested (i.e., naltrexone, growth factors, aldose reductase inhibitors, and antioxidants), and a few examples reported their sustained release by drug-eluting CLs. Preliminary clinical tests were conducted with therapeutic CLs releasing epidermal growth factors with encouraging results. However, extended experimentation is required due to the limited number of patients involved. Interestingly, the use of therapeutic CLs eluting aldose reductase inhibitors or antioxidants could have a double effect on both corneal issues and cataract prevention in the diabetic eye. In fact, the possibility of simultaneous treatment of different diseases could be an appealing objective in the design of therapeutic lenses that are addressed to diabetic patients due to the relationship between several ocular pathologies and chronic hyperglycemia.

The treatment of disorders of the posterior segment of the eye, in particular AMD, $\mathrm{DR}$, and DME, is a challenging topic in ocular drug delivery. The standard of care consists in laser treatments or invasive intravitreal injections. The possibility of using therapeutic lenses for the treatment of the posterior segment of the eye is almost unexplored. Despite this, a few in vivo studies detected drug amounts in the retina after drug delivery through therapeutic CLs. Based on the reported cases, further research on the ocular drug delivery pathway to the posterior segment and the therapeutic efficacy of ophthalmic lenses to target tissues in the back of the eye is suggested. In fact, future in vivo studies could evidence the suitability of previously developed devices for drug delivery to the retina. The incorporation of innovative drug delivery methods, such as drug-eluting nanoparticles, into ophthalmic lenses could also constitute an interesting future approach for a minimally invasive sustained drug delivery to the back of the eye. 
Surprisingly, the impressive efforts that were made by researchers around the world on the optimization of drug-eluting ophthalmic lenses did not yet result in the commercialization of these devices. As recently described by Lanier et al. [215], several reasons may be pointed out for the apparent lack of interest of the pharmaceutical industry to invest in those systems.

One common limitation of all innovative methods referred above is the need for the optimization of each specific system drug/lens. In fact, it is not possible to extrapolate the results that were obtained with a so-called model drug, because the drug release behavior and eventual alterations of the physical properties of the lenses after loading depend on the specific interactions between the drug and the polymeric matrix. For example, when using the molecular imprinting technique, the optimization of each combination polymer/monomer/crosslinker/template must be done. The control of the drug release by coating the lens strongly depends on the characteristics of the drug molecule: a very efficient coating for one drug may be inefficient for other similar drugs. Besides choosing the ideal combinations of components, it is also necessary to determine the adequate amounts of drug loaded: it has to be sufficient to ensure clinically relevant therapeutic release, but it cannot affect key aspects of the lens, namely transparency, Young modulus, ionic and oxygen permeability, wettability, and water content. In the case of the addition of other agents capable of sustaining the drug release, such as the functional monomers in the imprinting technique, vitamin E or surfactants, the preservation of the lens properties has to be ensured. The optimization of the combination of materials and loading conditions may be still more demanding when multiple drugs are needed for the treatment.

Some of the methods of preparation of drug-loaded lenses involve complex manufacturing, namely the incorporation of nanoparticles or drug reservoirs, the LbL coating, supercritical impregnation, which may be a drawback for scaling up production. Important issues, like the lack of drug stability during processing, the prevention of burst release, protein adherence, sterilization, and storage conditions, have been addressed but need more intense investigation.

In general, several innovative drug-eluting lenses have been submitted to in vivo studies, which demonstrated promising results; however, further studies involving the assessment of long-term safety are missing as well as extended clinical tests.

Fortunately, there are solutions for many of the technical problems described above. The minimization of burst release and protein adherence may be achieved with adequate coatings and/or optimized formulations. The storage conditions may involve immersion of the lenses in drug solutions, due to the equilibrium loading method, or keeping the lenses in dry state. Sterilization methods, which have no detrimental effects, have been proposed. Thus, the last step before commercialization needs a positive evaluation of the costs and benefits. The benefits seem to be huge, when considering that drug-eluting CLs may decrease the risks that are associated with their usual wear (keratitis, corneal erosion, dry eye syndrome, conjunctivitis) and avoid the frequent administration of eye drops for the treatment of ocular diseases, while drug-loaded IOLs may substitute the invasive intracameral and intravitreal injections. Thus, the commercialization of drugloaded ophthalmic lenses is probable in the near future, and ongoing research on this subject continues to be relevant.

Author Contributions: Conceptualization, N.T., B.S., A.P.S.; Methodology, N.T., B.S., A.P.S.; Formal Analysis, N.T.; Investigation, N.T.; Data Curation, N.T.; Writing-Original Draft Preparation, N.T.; Writing-Review \& Editing, N.T., B.S., A.P.S.; Supervision, B.S., A.P.S.; Project Administration, A.P.S.; Funding Acquisition, A.P.S. All authors have read and agreed to the published version of the manuscript.

Funding: This project has received funding from the European Union's Horizon 2020 research and innovation programme under the Marie Skłodowska-Curie grant agreement N 813440 (ORBITALOcular Research by Integrated Training And Learning).

Institutional Review Board Statement: Not applicable. 
Informed Consent Statement: Not applicable.

Data Availability Statement: Data sharing not applicable.

Acknowledgments: Graphical abstract was created using Servier Medical Art by Servier, which is licensed under a Creative Commons Attribution 3.0 Unported License.

Conflicts of Interest: The authors declare no conflict of interest.

Glossary

Medical terms

AGEs

AMD

CLs

DME

DR

IOLs

IOP

Advanced glycation end products

Age-related macular degeneration

Contact lenses

Diabetic macular edema

PCME

Diabetic retinopathy

Intraocular lenses

$\mathrm{PCO}$

Intraocular pressure

Pseudophakic cystoid macular edema

Posterior capsule opacification

Therapeutics/drugs

ARI(s)

EGF

Aldose reductase inhibitor(s)

LF

Epidermal growth factor

MMPI

Lactoferrin

MTX

Matrix metalloproteinases inhibitors

NSAIDs

Methotrexate

NTX

Non-steroidal anti-inflammatory drugs

PDGF

Naltrexone

TM

Platelet-derived growth factor

anti-VEGF

Timolol maleate

Vascular endothelial growth factor inhibitor

Materials and processing terms

(p)HEMA

PBS

(poly)hydroxyethyl methacrylate

Sil

Phosphate buffered saline

PGT

Siloxane macromers

EGDMA

PEG

PLA

PNIPAM

MAA

MA

Propoxylated glyceryl triacylate

DMA

PLGA

PDMS

APMA

MMA

BEM

Ethylene glycol dimethacrylate

Polyethylene glycol

Polylactide

Poly- $n$-isopropylacrylamide

Methacrylic acid

Methyl acrylate

$\mathrm{N}, \mathrm{N}$-dimethylacrylamide

Poly(lactic-co-glycolic acid)

Poly(dimethyl)siloxane

PVA

Aminopropyl methacrylamide

Methyl methacrylate

HA

HPMC

2-butoxyethyl methacrylate

Polyvinyl alcohol

Hyaluronic acid

$\mathrm{LbL}$

Hydroxypropyl methylcellulose

NVP

Layer-by-layer

PVP

$\mathrm{N}$-vinylpyrrolidone

GNP

Polyvinylpyrrolidone

GMA

Gold nanoparticles

PC

Glycidyl methacrylate

IBM

Phosphorylcholine

HBM

Isobornyl methacrylate

2-hydroxybutyl methacrylate 


$\begin{array}{ll}\text { MVA } & N \text {-methyl-N-vinylacetamide } \\ \text { PEA } & \text { Phenylethyl acrylate } \\ \text { PEMA } & \text { Phenylethyl methacrylate } \\ \text { BMA } & \text { Benzyl methacrylate } \\ \text { EGPEM } & \text { Ethyleneglycolphenylether methacrylate }\end{array}$

\section{References}

1. Shatz, W.; Aaronson, J.; Yohe, S.; Kelley, R.F.; Kalia, Y.N. Strategies for modifying drug residence time and ocular bioavailability to decrease treatment frequency for back of the eye diseases. Expert Opin. Drug Deliv. 2019, 16, 43-57. [CrossRef] [PubMed]

2. Khalaj, M.; Barikani, A.; Ghasemi, H. Eye disorders in old people. Glob. J. Health Sci. 2013, 5, 79-86. [CrossRef] [PubMed]

3. Balyeat, R.M.; Bowen, R. Allergic conjunctivitis. Community Eye Health J. 2017, 29, S7-S10. [CrossRef]

4. Priyavarshini, R.; Amit, B.P. Recent development in the artificial treatment for dry eye disease. Int. J. Res. Pharm. Sci. 2020, 11, 1902-1907. [CrossRef]

5. Song, B.J.; Aiello, L.P.; Pasquale, L.R. Presence and Risk Factors for Glaucoma in Patients with Diabetes. Curr. Diabetes Rep. 2016, 16, 124. [CrossRef] [PubMed]

6. Williams, R.; Airey, M.; Baxter, H.; Forrester, J.; Kennedy-Martin, T.; Girach, A. Epidemiology of diabetic retinopathy and macular oedema: A systematic review. Eye 2004, 18, 963-983. [CrossRef]

7. Shah, T.J.; Conway, M.D.; Peyman, G.A. Intracameral dexamethasone injection in the treatment of cataract surgery induced inflammation: Design, development, and place in therapy. Clin. Ophthalmol. 2018, 12, 2223-2235. [CrossRef]

8. Tyson, S.L.; Bailey, R.; Roman, J.S.; Zhan, T.; Hark, L.A.; Haller, J.A. Clinical outcomes after injection of a compounded pharmaceutical for prophylaxis after cataract surgery: A large-scale review. Curr. Opin. Ophthalmol. 2017, 28, 73-80. [CrossRef]

9. Hermann, M.M.; Stündag, C.Ü.; Diestelhorst, M. Electronic compliance monitoring of topical treatment after ophthalmic surgery. Int. Ophthalmol. 2010, 30, 385-390. [CrossRef]

10. Xu, J.; Xue, Y.; Hu, G.; Lin, T.; Gou, J.; Yin, T.; He, H.; Zhang, Y.; Tang, X. A comprehensive review on contact lens for ophthalmic drug delivery. J. Control. Release 2018, 281, 97-118. [CrossRef]

11. An, J.A.; Kasner, O.; Samek, D.A.; Lévesque, V. Evaluation of eyedrop administration by inexperienced patients after cataract surgery. J. Cataract Refract. Surg. 2014, 40, 1857-1861. [CrossRef] [PubMed]

12. Cooper, R.C.; Yang, H. Hydrogel-based ocular drug delivery systems: Emerging fabrication strategies, applications, and bench-to-bedside manufacturing considerations. J. Control. Release 2019, 306, 29-39. [CrossRef] [PubMed]

13. Jünemann, A.G.M.; Choragiewicz, T.; Ozimek, M.; Grieb, P.; Rejdak, R. Drug bioavailability from topically applied ocular drops. Does drop size matter? Ophthalmol. J. 2016, 1, 29-35. [CrossRef]

14. Ramsay, E.; del Amo, E.M.; Toropainen, E.; Tengvall-Unadike, U.; Ranta, V.P.; Urtti, A.; Ruponen, M. Corneal and conjunctival drug permeability: Systematic comparison and pharmacokinetic impact in the eye. Eur. J. Pharm. Sci. 2018, 119, 83-89. [CrossRef]

15. Kim, Y.C.; Chiang, B.; Wu, X.; Prausnitz, M.R. Ocular delivery of macromolecules. J. Control. Release 2014, 190, 172-181. [CrossRef]

16. Nagai, N.; Nakazawa, Y.; Ito, Y.; Kanai, K.; Okamoto, N.; Shimomura, Y. A nanoparticle-based ophthalmic formulation of dexamethasone enhances corneal permeability of the drug and prolongs its corneal residence time. Biol. Pharm. Bull. 2017, 40, 1055-1062. [CrossRef] [PubMed]

17. Chang, D.T.W.; Herceg, M.C.; Bilonick, R.A.; Camejo, L.; Schuman, J.S.; Noecker, R.J. Intracameral dexamethasone reduces inflammation on the first postoperative day after cataract surgery in eyes with and without glaucoma. Clin. Ophthalmol. 2009, 3, 345-355. [CrossRef] [PubMed]

18. Kiernan, D.F.; Hariprasad, S.M. Controversies in the management of Irvine-Gass syndrome. Ophthalmic Surg. Lasers Imaging 2013, 44, 522-527. [CrossRef] [PubMed]

19. Grzybowski, A.; Kanclerz, P. The Role of Steroids and NSAIDs in Prevention and Treatment of Postsurgical Cystoid Macular Edema. Curr. Pharm. Des. 2019, 24, 4896-4902. [CrossRef]

20. Nayak, K.; Misra, M. A review on recent drug delivery systems for posterior segment of eye. Biomed. Pharmacother. 2018, 107, 1564-1582. [CrossRef]

21. Hui, A. Contact lenses for ophthalmic drug delivery. Clin. Exp. Optom. 2017, 100, 494-512. [CrossRef]

22. Maulvi, F.A.; Soni, T.G.; Shah, D.O. A review on therapeutic contact lenses for ocular drug delivery. Drug Deliv. 2016, 23, 3017-3026. [CrossRef]

23. Garty, S.; Shirakawa, R.; Warsen, A.; Anderson, E.M.; Noble, M.L.; Bryers, J.D.; Ratner, B.D.; Shen, T.T. Sustained antibiotic release from an intraocular lens-hydrogel assembly for cataract surgery. Investig. Ophthalmol. Vis. Sci. 2011, 52, 6109-6116. [CrossRef]

24. Topete, A.; Serro, A.P.; Saramago, B. Dual drug delivery from intraocular lens material for prophylaxis of endophthalmitis in cataract surgery. Int. J. Pharm. 2019, 558, 43-52. [CrossRef]

25. Li, X.; Zhao, Y.; Wang, K.; Wang, L.; Yang, X.; Zhu, S. Cyclodextrin-containing hydrogels as an intraocular lens for sustained drug release. PLoS ONE 2017, 12, e0189778. [CrossRef]

26. Bouledjouidja, A.; Masmoudi, Y.; Sergent, M.; Trivedi, V.; Meniai, A.; Badens, E. Drug loading of foldable commercial intraocular lenses using supercritical impregnation. Int. J. Pharm. 2016, 500, 85-99. [CrossRef]

27. Eperon, S.; Bossy-Nobs, L.; Petropoulos, I.K.; Gurny, R.; Guex-Crosier, Y. A biodegradable drug delivery system for the treatment of postoperative inflammation. Int. J. Pharm. 2008, 352, 240-247. [CrossRef] 
28. Fonn, D.; Sweeney, D. The Benefits of Silicone Hydrogel Daily Disposable Lenses: A look at why silicone hydrogel daily disposable lenses are our preferred option for daily wear. Contact Lens Spectr. 2015, 30, 42-45.

29. Moreddu, R.; Vigolo, D.; Yetisen, A.K. Contact Lens Technology: From Fundamentals to Applications. Adv. Healthc. Mater. 2019, 8, 1900368. [CrossRef]

30. Mohammadi, S.; Jones, L.; Gorbet, M. Extended latanoprost release from commercial contact lenses: in vitro studies using corneal models. PLoS ONE 2014, 9, e106653. [CrossRef]

31. Schultz, C.; Breaux, J.; Schentag, J.; Morck, D. Drug delivery to the posterior segment of the eye through hydrogel contact lenses. Clin. Exp. Optom. 2011, 94, 212-218. [CrossRef]

32. Davis, J.L.; Yi, N.Y.; Salmon, J.H.; Charlton, A.N.; Colitz, C.M.H.; Gilger, B.C. Sustained-release celecoxib from incubated acrylic intraocular lenses suppresses lens epithelial cell growth in an ex vivo model of posterior capsule opacity. J. Ocul. Pharmacol. Ther. 2012, 28, 359-368. [CrossRef]

33. Wertheimer, C.; Brandlhuber, U.; Kook, D.; Mayer, W.J.; Laubichler, P.; Wolf, A.; Kampik, A.; Eibl-Lindner, K. Erufosine, a phosphoinositide-3-kinase inhibitor, to mitigate posterior capsule opacification in the human capsular bag model. J. Cataract Refract. Surg. 2015, 41, 1484-1489. [CrossRef]

34. Wertheimer, C.; Kueres, A.; Siedlecki, J.; Braun, C.; Kassumeh, S.; Wolf, A.; Mayer, W.; Priglinger, C.; Priglinger, S.; Eibl-Lindner, K. The intraocular lens as a drug delivery device for an epidermal growth factor-Receptor inhibitor for prophylaxis of posterior capsule opacification. Acta Ophthalmol. 2018, 96, e874-e882. [CrossRef]

35. Kassumeh, S.; Kueres, A.; Hillenmayer, A.; von Studnitz, A.; Elhardt, C.; Ohlmann, A.; Priglinger, S.G.; Wertheimer, C.M. Development of a drug-eluting intraocular lens to deliver epidermal growth factor receptor inhibitor gefitinib for posterior capsule opacification prophylaxis. Eur. J. Ophthalmol. 2019. [CrossRef]

36. Wertheimer, C.; Kassumeh, S.; Piravej, N.P.; Nilmayer, O.; Braun, C.; Priglinger, C.; Luft, N.; Wolf, A.; Mayer, W.J.; Priglinger, S.G.; et al. The intraocular lens as a drug delivery device: in vitro screening of pharmacologic substances for the prophylaxis of posterior capsule opacification. Investig. Ophthalmol. Vis. Sci. 2017, 58, 6408-6418. [CrossRef]

37. Atabek Yigit, E.; Ercal, N. Release of N-acetylcysteine and N-acetylcysteine amide from contact lenses. Eye Contact Lens 2013, 39, 335-340. [CrossRef]

38. Horne, R.R.; Rich, J.T.; Bradley, M.W.; Pitt, W.G. Latanoprost uptake and release from commercial contact lenses. J. Biomater. Sci. Polym. Ed. 2020, 31, 1-19. [CrossRef]

39. Lipnitzki, I.; Bronshtein, R.; Ben Eliahu, S.; Marcovich, A.L.; Kleinmann, G. Hydrophilic acrylic intraocular lens as a drug delivery system: Influence of the presoaking time and comparison to intracameral injection. J. Ocul. Pharmacol. Ther. 2013, 29, 414-418. [CrossRef]

40. Topete, A.; Oliveira, A.S.; Fernandes, A.; Nunes, T.G.; Serro, A.P.; Saramago, B. Improving sustained drug delivery from ophthalmic lens materials through the control of temperature and time of loading. Eur. J. Pharm. Sci. 2018, 117, 107-117. [CrossRef]

41. Filipe, H.P.; Bozukova, D.; Pimenta, A.; Vieira, A.P.; Oliveira, A.S.; Galante, R.; Topete, A.; Masson, M.; Alves, P.; Coimbra, P.; et al. Moxifloxacin-loaded acrylic intraocular lenses: in vitro and in vivo performance. J. Cataract Refract. Surg. 2019, 45, 1808-1817. [CrossRef]

42. Pimenta, A.F.R.; Serro, A.P.; Colaço, R.; Chauhan, A. Optimization of intraocular lens hydrogels for dual drug release: Experimentation and modelling. Eur. J. Pharm. Biopharm. 2019, 141, 51-57. [CrossRef]

43. Schultz, C.L.; Morck, D.W. Contact lenses as a drug delivery device for epidermal growth factor in the treatment of ocular wounds. Clin. Exp. Optom. 2010, 93, 61-65. [CrossRef]

44. Pastori, V.; Tavazzi, S.; Lecchi, M. Lactoferrin-loaded contact lenses: Eye protection against oxidative stress. Cornea 2015, 34, 693-697. [CrossRef]

45. Pastori, V.; Tavazzi, S.; Lecchi, M. Lactoferrin-loaded contact lenses counteract cytotoxicity caused in vitro by keratoconic tears. Contact Lens Anterior Eye 2019, 42, 253-257. [CrossRef]

46. González-Chomón, C.; Concheiro, A.; Alvarez-Lorenzo, C. Drug-eluting intraocular lenses. Materials 2011, 4, 1927-1940. [CrossRef]

47. Liu, Y.C.; Wong, T.T.; Mehta, J.S. Intraocular lens as a drug delivery reservoir. Curr. Opin. Ophthalmol. 2013, 24, 53-59. [CrossRef]

48. Madni, A.; Rahem, M.A.; Tahir, N.; Sarfraz, M.; Jabar, A.; Rehman, M.; Kashif, P.M.; Badshah, S.F.; Khan, K.U.; Santos, H.A. Non-invasive strategies for targeting the posterior segment of eye. Int. J. Pharm. 2017, 530, 326-345. [CrossRef]

49. Dixon, P.; Chauhan, A. Effect of the surface layer on drug release from delefilcon-A (Dailies Total1 ${ }^{\circledR}$ ) contact lenses. Int. J. Pharm. 2017, 529, 89-101. [CrossRef]

50. $\mathrm{Xu}, \mathrm{J} . ; \mathrm{Li}, \mathrm{X} . ;$ Sun, F. Cyclodextrin-containing hydrogels for contact lenses as a platform for drug incorporation and release. Acta Biomater. 2010, 6, 486-493. [CrossRef]

51. García-Fernández, M.J.; Tabary, N.; Martel, B.; Cazaux, F.; Oliva, A.; Taboada, P.; Concheiro, A.; Alvarez-Lorenzo, C. Poly(cyclo)dextrins as ethoxzolamide carriers in ophthalmic solutions and in contact lenses. Carbohydr. Polym. 2013, 98, $1343-1352$. [CrossRef]

52. Hsu, K.H.; Carbia, B.E.; Plummer, C.; Chauhan, A. Dual drug delivery from vitamin e loaded contact lenses for glaucoma therapy. Eur. J. Pharm. Biopharm. 2015, 94, 312-321. [CrossRef] 
53. Sekar, P.; Chauhan, A. Effect of vitamin-E integration on delivery of prostaglandin analogs from therapeutic lenses. J. Colloid Interface Sci. 2019, 539, 457-467. [CrossRef]

54. Lee, D.; Cho, S.; Park, H.S.; Kwon, I. Ocular drug delivery through pHEMA-Hydrogel contact lenses Co-loaded with lipophilic vitamins. Sci. Rep. 2016, 6, 34194. [CrossRef]

55. Peng, C.C.; Ben-Shlomo, A.; MacKay, E.O.; Plummer, C.E.; Chauhan, A. Drug delivery by contact lens in spontaneously glaucomatous dogs. Curr. Eye Res. 2012, 37, 204-211. [CrossRef]

56. Peng, C.C.; Burke, M.T.; Carbia, B.E.; Plummer, C.; Chauhan, A. Extended drug delivery by contact lenses for glaucoma therapy. J. Control. Release 2012, 162, 152-158. [CrossRef]

57. Kim, J.; Peng, C.C.; Chauhan, A. Extended release of dexamethasone from silicone-hydrogel contact lenses containing vitamin E. J. Control. Release 2010, 148, 110-116. [CrossRef]

58. Torres-Luna, C.; Koolivand, A.; Fan, X.; Agrawal, N.R.; Hu, N.; Zhu, Y.; Domszy, R.; Briber, R.M.; Wang, N.S.; Yang, A. Formation of drug-participating catanionic aggregates for extended delivery of non-steroidal anti-inflammatory drugs from contact lenses. Biomolecules 2019, 9, 593. [CrossRef]

59. Andrade-Vivero, P.; Fernandez-Gabriel, E.; Alvarez-Lorenzo, C.; Concheiro, A. Improving the Loading and Release of NSAIDs frompHEMA Hydrogels by Copolymerization withFunctionalized Monomers. J. Pharm. Sci. 2007, 96, 802-813. [CrossRef]

60. González-Chomón, C.; Braga, M.E.M.; De Sousa, H.C.; Concheiro, A.; Alvarez-Lorenzo, C. Antifouling foldable acrylic IOLs loaded with norfloxacin by aqueous soaking and by supercritical carbon dioxide technology. Eur. J. Pharm. Biopharm. 2012, 82, 383-391. [CrossRef]

61. Xu, J.; Li, X.; Sun, F. Preparation and evaluation of a contact lens vehicle for puerarin delivery. J. Biomater. Sci. Polym. Ed. 2010, 21, 271-288. [CrossRef]

62. Kakisu, K.; Matsunaga, T.; Kobayakawa, S.; Sato, T.; Tochikubo, T. Development and efficacy of a drug-releasing soft contact lens. Investig. Ophthalmol. Vis. Sci. 2013, 54, 2551-2561. [CrossRef]

63. Soluri, A.; Hui, A.; Jones, L. Delivery of ketotifen fumarate by commercial contact lens materials. Optom. Vis. Sci. 2012, 89, 1140-1149. [CrossRef]

64. Kassumeh, S.A.; Wertheimer, C.M.; von Studnitz, A.; Hillenmayer, A.; Priglinger, C.; Wolf, A.; Mayer, W.J.; Teupser, D.; Holdt, L.M.; Priglinger, S.G.; et al. Poly(lactic-co-glycolic) Acid as a Slow-Release Drug-Carrying Matrix for Methotrexate Coated onto Intraocular Lenses to Conquer Posterior Capsule Opacification. Curr. Eye Res. 2018, 43, 702-708. [CrossRef]

65. Manju, S.; Kunnatheeri, S. Layer-by-Layer modification of poly (methyl methacrylate) intra ocular lens: Drug delivery applications. Pharm. Dev. Technol. 2010, 15, 379-385. [CrossRef]

66. Pimenta, A.F.R.; Vieira, A.P.; Colaço, R.; Saramago, B.; Gil, M.H.; Coimbra, P.; Alves, P.; Bozukova, D.; Correia, T.R.; Correia, I.J.; et al. Controlled release of moxifloxacin from intraocular lenses modified by Ar plasma-assisted grafting with AMPS or SBMA: An in vitro study. Colloids Surf. B Biointerfaces 2017, 156, 95-103. [CrossRef]

67. Mehta, P.; Al-Kinani, A.A.; Haj-Ahmad, R.; Arshad, M.S.; Chang, M.W.; Alany, R.G.; Ahmad, Z. Electrically atomised formulations of timolol maleate for direct and on-demand ocular lens coatings. Eur. J. Pharm. Biopharm. 2017, 119, 170-184. [CrossRef]

68. Mehta, P.; Al-Kinani, A.A.; Arshad, M.S.; Chang, M.W.; Alany, R.G.; Ahmad, Z. Development and characterisation of electrospun timolol maleate-loaded polymeric contact lens coatings containing various permeation enhancers. Int. J. Pharm. 2017, 532, 408-420. [CrossRef]

69. Mehta, P.; Al-Kinani, A.A.; Arshad, M.S.; Singh, N.; van der Merwe, S.M.; Chang, M.W.; Alany, R.G.; Ahmad, Z. Engineering and Development of Chitosan-Based Nanocoatings for Ocular Contact Lenses. J. Pharm. Sci. 2019, 108, 1540-1551. [CrossRef]

70. Silva, D.; Pinto, L.F.V.; Bozukova, D.; Santos, L.F.; Serro, A.P.; Saramago, B. Chitosan/alginate based multilayers to control drug release from ophthalmic lens. Colloids Surf. B Biointerfaces 2016, 147, 81-89. [CrossRef]

71. Vieira, A.P.; Pimenta, A.F.R.; Silva, D.; Gil, M.H.; Alves, P.; Coimbra, P.; Mata, J.L.G.C.; Bozukova, D.; Correia, T.R.; Correia, I.J.; et al Surface modification of an intraocular lens material by plasma-assisted grafting with 2-hydroxyethyl methacrylate (HEMA), for controlled release of moxifloxacin. Eur. J. Pharm. Biopharm. 2017, 120, 52-62. [CrossRef]

72. Liu, H.; Zhang, Y.; Ma, H.; Zhang, C.; Fu, S. Comparison of posterior capsule opacification in rabbit eyes receiving different administrations of rapamycin. Graefe's Arch. Clin. Exp. Ophthalmol. 2014, 252, 1111-1118. [CrossRef]

73. Lin, L.; Lin, Q.; Li, J.; Han, Y.; Chang, P.; Lu, F.; Zhao, Y.E. ROCK inhibitor modified intraocular lens as an approach for inhibiting the proliferation and migration of lens epithelial cells and posterior capsule opacification. Biomater. Sci. 2019, 7, 4208-4217. [CrossRef]

74. Han, Y.; Tang, J.; Xia, J.; Wang, R.; Qin, C.; Liu, S.; Zhao, X.; Chen, H.; Lin, Q. Anti-adhesive and antiproliferative synergistic surface modification of intraocular lens for reduced posterior capsular opacification. Int. J. Nanomed. 2019, 14, 9047-9061. [CrossRef]

75. Silva, D.; Sousa, H.C.D.; Gil, M.H.; Santos, L.F.; Moutinho, G.M.; Serro, A.P.; Saramago, B. Antibacterial layer-by-layer coatings to control drug release from soft contact lenses material. Int. J. Pharm. 2018, 553, 186-200. [CrossRef]

76. Paradiso, P.; Colaço, R.; Mata, J.L.G.; Krastev, R.; Saramago, B.; Serro, A.P. Drug release from liposome coated hydrogels for soft contact lenses: The blinking and temperature effect. J. Biomed. Mater. Res. Part. B Appl. Biomater. 2017, 105, 1799-1807. [CrossRef]

77. Zhang, Z.; Huang, W.; Lei, M.; He, Y.; Yan, M.; Zhang, X.; Zhao, C. Laser-triggered intraocular implant to induce photodynamic therapy for posterior capsule opacification prevention. Int. J. Pharm. 2016, 498, 1-11. [CrossRef] 
78. Alvarez-Lorenzo, C.; Concheiro, A. Molecularly imprinted materials as advanced excipients for drug delivery systems. Biotechnol. Annu. Rev. 2006, 12, 225-268. [CrossRef]

79. Alvarez-Lorenzo, C.; Yañez, F.; Concheiro, A. Ocular drug delivery from molecularly-imprinted contact lenses. J. Drug Deliv. Sci. Technol. 2010, 20, 237-248. [CrossRef]

80. Alvarez-Lorenzo, C.; Anguiano-Igea, S.; Varela-García, A.; Vivero-Lopez, M.; Concheiro, A. Bioinspired hydrogels for drug-eluting contact lenses. Acta Biomater. 2019, 84, 49-62. [CrossRef]

81. White, C.J.; McBride, M.K.; Pate, K.M.; Tieppo, A.; Byrne, M.E. Extended release of high molecular weight hydroxypropyl methylcellulose from molecularly imprinted, extended wear silicone hydrogel contact lenses. Biomaterials 2011, 32, 5698-5705. [CrossRef] [PubMed]

82. Anirudhan, T.S.; Nair, A.S.; Parvathy, J. Extended wear therapeutic contact lens fabricated from timolol imprinted carboxymethyl chitosan-g-hydroxy ethyl methacrylate-g-poly acrylamide as a onetime medication for glaucoma. Eur. J. Pharm. Biopharm. 2016, 109, 61-71. [CrossRef] [PubMed]

83. Yan, F.; Liu, Y.; Han, S.; Zhao, Q.; Liu, N. Bimatoprost Imprinted Silicone Contact Lens to Treat Glaucoma. AAPS Pharmscitech 2020, 21, 63. [CrossRef] [PubMed]

84. Ribeiro, A.; Veiga, F.; Santos, D.; Torres-Labandeira, J.J.; Concheiro, A.; Alvarez-Lorenzo, C. Bioinspired Imprinted PHEMAHydrogels for ocular delivery of carbonic anhydrase inhibitor drugs. Biomacromolecules 2011, 12, 701-709. [CrossRef] [PubMed]

85. Ribeiro, A.; Veiga, F.; Santos, D.; Torres-Labandeira, J.J.; Concheiro, A.; Alvarez-Lorenzo, C. Receptor-based biomimetic NVP/DMA contact lenses for loading/eluting carbonic anhydrase inhibitors. J. Membr. Sci. 2011, 383, 60-69. [CrossRef]

86. Deng, J.; Chen, S.; Chen, J.; Ding, H.; Deng, D.; Xie, Z. Self-Reporting Colorimetric Analysis of Drug Release by Molecular Imprinted Structural Color Contact Lens. ACS Appl. Mater. Interfaces 2018, 10, 34611-34617. [CrossRef]

87. Alvarez-Rivera, F.; Serro, A.P.; Silva, D.; Concheiro, A.; Alvarez-Lorenzo, C. Hydrogels for diabetic eyes: Naltrexone loading, release profiles and cornea penetration. Mater. Sci. Eng. C 2019, 105, 10092. [CrossRef]

88. Alvarez-Rivera, F.; Concheiro, A.; Alvarez-Lorenzo, C. Epalrestat-loaded silicone hydrogels as contact lenses to address diabeticeye complications. Eur. J. Pharm. Biopharm. 2018, 122, 126-136. [CrossRef]

89. White, C.J.; Tieppo, A.; Byrne, M.E. Controlled drug release from contact lenses: A comprehensive review from 1965-present. J. Drug Deliv. Sci. Technol. 2011, 21,369-384. [CrossRef]

90. Zaidi, S.A. Latest trends in molecular imprinted polymer based drug delivery systems. RSC Adv. 2016, 6, 88807-88819. [CrossRef]

91. Hiratani, H.; Mizutani, Y.; Alvarez-Lorenzo, C. Controlling drug release from imprinted hydrogels by modifying the characteristics of the imprinted cavities. Macromol. Biosci. 2005, 5, 728-733. [CrossRef]

92. Bouledjouidja, A.; Masmoudi, Y.; Sergent, M.; Badens, E. Effect of operational conditions on the supercritical carbon dioxide impregnation of anti-inflammatory and antibiotic drugs in rigid commercial intraocular lenses. J. Supercrit. Fluids 2017, 130, 63-75. [CrossRef]

93. Costa, V.P.; Braga, M.E.M.; Guerra, J.P.; Duarte, A.R.C.; Duarte, C.M.M.; Leite, E.O.B.; Gil, M.H.; de Sousa, H.C. Development of therapeutic contact lenses using a supercritical solvent impregnation method. J. Supercrit. Fluids 2010, 52, 306-316. [CrossRef]

94. Costa, V.P.; Braga, M.E.M.; Duarte, C.M.M.; Alvarez-Lorenzo, C.; Concheiro, A.; Gil, M.H.; de Sousa, H.C. Anti-glaucoma drug-loaded contact lenses prepared using supercritical solvent impregnation. J. Supercrit. Fluids 2010, 53, 165-173. [CrossRef]

95. Bouledjouidja, A.; Masmoudi, Y.; Li, Y.; He, W.; Badens, E. Supercritical impregnation and optical characterization of loaded foldable intraocular lenses using supercritical fluids. J. Cataract Refract. Surg. 2017, 43, 1343-1349. [CrossRef]

96. Ongkasin, K.; Masmoudi, Y.; Tassaing, T.; Le-Bourdon, G.; Badens, E. Supercritical loading of gatifloxacin into hydrophobic foldable intraocular lenses-Process control and optimization by following in situ $\mathrm{CO}_{2}$ sorption and polymer swelling. Int. J. Pharm. 2020, 581, 119247. [CrossRef]

97. Ongkasin, K.; Masmoudi, Y.; Wertheimer, C.M.; Hillenmayer, A.; Eibl-Lindner, K.H.; Badens, E. Supercritical fluid technology for the development of innovative ophthalmic medical devices: Drug loaded intraocular lenses to mitigate posterior capsule opacification. Eur. J. Pharm. Biopharm. 2020, 149, 248-256. [CrossRef]

98. Masmoudi, Y.; Ben Azzouk, L.; Forzano, O.; Andre, J.M.; Badens, E. Supercritical impregnation of intraocular lenses. J. Supercrit. Fluids 2011, 60, 98-105. [CrossRef]

99. Yokozaki, Y.; Sakebe, J.; Ng, B.; Shimoyama, Y. Effect of temperature, pressure and depressurization rate on release profile of salicylic acid from contact lenses prepared by supercritical carbon dioxide impregnation. Chem. Eng. Res. Des. 2015, 100, 89-94. [CrossRef]

100. Yañez, F.; Martikainen, L.; Braga, M.E.M.; Alvarez-Lorenzo, C.; Concheiro, A.; Duarte, C.M.M.; Gil, M.H.; De Sousa, H.C. Supercritical fluid-assisted preparation of imprinted contact lenses for drug delivery. Acta Biomater. 2011, 7, 1019-1030. [CrossRef]

101. Jung, H.J.; Abou-Jaoude, M.; Carbia, B.E.; Plummer, C.; Chauhan, A. Glaucoma therapy by extended release of timolol from nanoparticle loaded silicone-hydrogel contact lenses. J. Control. Release 2013, 165, 82-89. [CrossRef] [PubMed]

102. Jung, H.J.; Chauhan, A. Temperature sensitive contact lenses for triggered ophthalmic drug delivery. Biomaterials 2012, 33, 2289-2300. [CrossRef] [PubMed]

103. Kim, H.J.; Zhang, K.; Moore, L.; Ho, D. Diamond nanogel-embedded contact lenses mediate lysozyme-dependent therapeutic release. ACS Nano 2014, 8, 2998-3005. [CrossRef] [PubMed] 
104. Lee, S.H.; Kim, H.J.; Kim, D.H.; Chang, W.S.; Vales, T.P.; Kim, J.W.; Kim, K.H.; Kim, J.K. Thermo-sensitive nanogel-laden bicontinuous microemulsion drug-eluting contact lenses. J. Biomed. Mater. Res. Part. B Appl. Biomater. 2019, 107, 1159-1169. [CrossRef] [PubMed]

105. Han, Y.; Xu, X.; Wang, Y.; Liu, S.; Zhao, X.; Chen, H.; Lin, Q. Drug Eluting Intraocular Lens Surface Modification for PCO Prevention. Colloids Interface Sci. Commun. 2018, 24, 40-44. [CrossRef]

106. Huang, X.; Wang, Y.; Cai, J.P.; Ma, X.Y.; Li, Y.; Cheng, J.W.; Wei, R.L. Sustained release of 5-fluorouracil from chitosan nanoparticles surface modified intra ocular lens to prevent posterior capsule opacification: An in vitro and in vivo study. J. Ocul. Pharmacol Ther. 2013, 29, 208-215. [CrossRef]

107. Maulvi, F.A.; Patil, R.J.; Desai, A.R.; Shukla, M.R.; Vaidya, R.J.; Ranch, K.M.; Vyas, B.A.; Shah, S.A.; Shah, D.O. Effect of gold nanoparticles on timolol uptake and its release kinetics from contact lenses: in vitro and in vivo evaluation. Acta Biomater. 2019, 86, 350-362. [CrossRef]

108. Sharma, M.; Bhowmick, R.; Gappa-Fahlenkamp, H. Drug-Loaded Nanoparticles Embedded in a Biomembrane Provide a Dual-Release Mechanism for Drug Delivery to the Eye. J. Ocul. Pharmacol. Ther. 2016, 32, 565-573. [CrossRef]

109. De Jong, W.H.; Borm, P.J.A. Drug delivery and nanoparticles: Applications and hazards. Int. J. Nanomed. 2008, 3, 133-149. [CrossRef]

110. Rizvi, S.A.A.; Saleh, A.M. Applications of nanoparticle systems in drug delivery technology. Saudi Pharm. J. 2018, 26, 64-70. [CrossRef]

111. Dubald, M.; Bourgeois, S.; Andrieu, V.; Fessi, H. Ophthalmic drug delivery systems for antibiotherapy- A review. Pharmaceutics 2018, 10, 10. [CrossRef]

112. Mun, J.; Mok, J.W.; Jeong, S.; Cho, S.; Joo, C.K.; Hahn, S.K. Drug-eluting contact lens containing cyclosporine-loaded cholesterolhyaluronate micelles for dry eye syndrome. RSC Adv. 2019, 9, 16578-16585. [CrossRef]

113. Xu, J.; Ge, Y.; Bu, R.; Zhang, A.; Feng, S.; Wang, J.; Gou, J.; Yin, T.; He, H.; Zhang, Y.; et al. Co-delivery of latanoprost and timolol from micelles-laden contact lenses for the treatment of glaucoma. J. Control. Release 2019, 305, 18-28. [CrossRef]

114. Maulvi, F.A.; Desai, A.R.; Choksi, H.H.; Patil, R.J.; Ranch, K.M.; Vyas, B.A.; Shah, D.O. Effect of surfactant chain length on drug release kinetics from microemulsion-laden contact lenses. Int. J. Pharm. 2017, 524, 193-204. [CrossRef]

115. Xu, W.; Jiao, W.; Li, S.; Tao, X.; Mu, G. Bimatoprost loaded microemulsion laden contact lens to treat glaucoma. J. Drug Deliv. Sci. Technol. 2019, 54, 101330. [CrossRef]

116. Wei, N.; Dang, H.; Huang, C.; Sheng, Y. Timolol loaded microemulsion laden silicone contact lens to manage glaucoma: in vitro and in vivo studies. J. Dispers. Sci. Technol. 2020, 1-9. [CrossRef]

117. Siqueira, R.C.; Ribeiro Filho, E.; Fialho, S.L.; Lucena, L.R.; Maia Filho, A.; Haddad, A.; Jorge, R.; Scott, I.U.; Da Silva Cunha, A. Pharmacokinetic and toxicity investigations of a new intraocular lens with a dexamethasone drug delivery system: A pilot study. Ophthalmologica 2006, 220, 338-342. [CrossRef]

118. Tan, D.W.N.; Lim, S.G.; Wong, T.T.; Venkatraman, S.S. Sustained antibiotic-eluting intra-ocular lenses: A new approach. PLoS ONE 2016, 11, e0163857. [CrossRef]

119. Eperon, S.; Rodriguez-Aller, M.; Balaskas, K.; Gurny, R.; Guex-Crosier, Y. A new drug delivery system inhibits uveitis in an animal model after cataract surgery. Int. J. Pharm. 2013, 443, 254-261. [CrossRef]

120. Ross, A.E.; Bengani, L.C.; Tulsan, R.; Maidana, D.E.; Salvador-Culla, B.; Kobashi, H.; Kolovou, P.E.; Zhai, H.; Taghizadeh, K.; Kuang, L.; et al. Topical sustained drug delivery to the retina with a drug-eluting contact lens. Biomaterials 2019, $217,119285$. [CrossRef]

121. Maulvi, F.A.; Lakdawala, D.H.; Shaikh, A.A.; Desai, A.R.; Choksi, H.H.; Vaidya, R.J.; Ranch, K.M.; Koli, A.R.; Vyas, B.A.; Shah, D.O. vitro and in vivo evaluation of novel implantation technology in hydrogel contact lenses for controlled drug delivery. $J$. Control. Release 2016, 226, 47-56. [CrossRef] [PubMed]

122. Desai, A.R.; Maulvi, F.A.; Pandya, M.M.; Ranch, K.M.; Vyas, B.A.; Shah, S.A.; Shah, D.O. Co-delivery of timolol and hyaluronic acid from semi-circular ring-implanted contact lenses for the treatment of glaucoma: in vitro and in vivo evaluation. Biomater. Sci. 2018, 6, 1580-1591. [CrossRef] [PubMed]

123. Desai, A.R.; Maulvi, F.A.; Desai, D.M.; Shukla, M.R.; Ranch, K.M.; Vyas, B.A.; Shah, S.A.; Sandeman, S.; Shah, D.O. Multiple drug delivery from the drug-implants-laden silicone contact lens: Addressing the issue of burst drug release. Mater. Sci. Eng. C 2020, 112, 110885. [CrossRef] [PubMed]

124. Ciolino, J.B.; Stefanescu, C.F.; Ross, A.E.; Salvador-Culla, B.; Cortez, P.; Ford, E.M.; Wymbs, K.A.; Sprague, S.L.; Mascoop, D.R.; Rudina, S.S.; et al. in vivo performance of a drug-eluting contact lens to treat glaucoma for a month. Biomaterials 2014, 35, 432-439. [CrossRef]

125. Ciolino, J.B.; Ross, A.E.; Tulsan, R.; Watts, A.C.; Wang, R.F.; Zurakowski, D.; Serle, J.B.; Kohane, D.S. Latanoprost-Eluting Contact Lenses in Glaucomatous Monkeys. Ophthalmology 2016, 123, 2085-2092. [CrossRef]

126. Song, C.; Ben-Shlomo, G.; Que, L. A Multifunctional Smart Soft Contact Lens Device Enabled by Nanopore Thin Film for Glaucoma Diagnostics and in Situ Drug Delivery. J. Microelectromech. Syst. 2019, 28, 810-816. [CrossRef]

127. Weinreb, R.N.; Aung, T.; Medeiros, F.A. The Pathophysiology and Treatment of Glaucoma: A Review. JAMA 2014, $311,1901-1911$. [CrossRef]

128. Wong, V.H.Y.; Bui, B.V.; Vingrys, A.J. Clinical and experimental links between diabetes and glaucoma. Clin. Exp. Optom. 2011, 94, 4-23. [CrossRef] 
129. Hanyuda, A.; Sawada, N.; Yuki, K.; Uchino, M.; Ozawa, Y.; Sasaki, M.; Yamagishi, K.; Iso, H.; Tsubota, K.; Tsugane, S. Relationships of diabetes and hyperglycaemia with intraocular pressure in a Japanese population: The JPHC-NEXT Eye Study. Sci. Rep. 2020, 10, 5355. [CrossRef]

130. Gerber, A.L.; Harris, A.; Siesky, B.; Lee, E.; Schaab, T.J.; Huck, A.; Amireskandari, A. Vascular Dysfunction in Diabetes and Glaucoma: A Complex Relationship Reviewed. J. Glaucoma 2015, 24, 474-479. [CrossRef]

131. Capitena Young, C.E.; Kahook, M.Y.; Seibold, L.K. Novel Drug Delivery Systems for the Treatment of Glaucoma. Curr. Ophthalmol. Rep. 2019, 7, 143-149. [CrossRef]

132. Carvalho, I.M.; Marques, C.S.; Oliveira, R.S.; Coelho, P.B.; Costa, P.C.; Ferreira, D.C. Sustained drug release by contact lenses for glaucoma treatment-A review. J. Control. Release 2015, 202, 76-82. [CrossRef] [PubMed]

133. Szigiato, A.A.; Podbielski, D.W.; Ahmed, I.I.K. Sustained drug delivery for the management of glaucoma. Expert Rev. Ophthalmol. 2017, 12, 173-186. [CrossRef]

134. Sihota, R.; Angmo, D.; Ramaswamy, D.; Dada, T. Simplifying "target" intraocular pressure for different stages of primary open-angle glaucoma and primary angle-closure glaucoma. Indian J. Ophthalmol. 2018, 66, 495-505. [CrossRef]

135. Maulvi, F.A.; Soni, T.G.; Shah, D.O. Extended Release of Timolol from Ethyl Cellulose Microparticles Laden Hydrogel Contact Lenses. Open Pharm. Sci. J. 2015, 2, 1-12. [CrossRef]

136. Mu, C.; Shi, M.; Liu, P.; Chen, L.; Marriott, G. Daylight-Mediated, Passive, and Sustained Release of the Glaucoma Drug Timolol from a Contact Lens. ACS Cent. Sci. 2018, 4, 1677-1687. [CrossRef]

137. Lee, S.H.; Shin, K.S.; Kim, J.W.; Kang, J.Y.; Kim, J.K. Stimulus-responsive contact lens for IOP measurement or temperaturetriggered drug release. Transl Vis. Sci. Technol. 2020, 9, 1-10. [CrossRef]

138. Zhu, Q.; Cheng, H.; Huo, Y.; Mao, S. Sustained ophthalmic delivery of highly soluble drug using pH-triggered inner layerembedded contact lens. Int. J. Pharm. 2018, 544, 100-111. [CrossRef]

139. Peng, C.C.; Burke, M.T.; Chauhan, A. Transport of topical anesthetics in vitamin e loaded silicone hydrogel contact lenses. Langmuir 2012, 28, 1478-1487. [CrossRef]

140. Gupta, V.; Rajagopala, M.; Ravishankar, B. Etiopathogenesis of cataract: An appraisal. Indian J. Ophthalmol. 2014, 62, 103-110. [CrossRef]

141. McCarty, C.A. Cataract in the 21st century: Lessons from previous epidemiologic research. Clin. Exp. Optom. 2002, 85, 91-96. [CrossRef] [PubMed]

142. Laursen, S.B.; Erichsen, J.H.; Holm, L.M.; Kessel, L. Prevention of macular edema in patients with diabetes after cataract surgery. J. Cataract Refract. Surg. 2019, 45, 854-869. [CrossRef] [PubMed]

143. Pollreisz, A.; Schmidt-Erfurth, U. Diabetic Cataract_Pathogenesis, Epidemiology and Treatment. J. Ophthalmol. 2010, $2010,608751$. [CrossRef] [PubMed]

144. Varela-Garcia, A.; Concheiro, A.; Alvarez-Lorenzo, C. Cytosine-functionalized bioinspired hydrogels for ocular delivery of antioxidant transferulic acid. Biomater. Sci. 2020, 8, 1171-1180. [CrossRef]

145. Dua, H.S.; Attre, R. Treatment of Post-operative Inflammation following Cataract Surgery-A Review. Eur. Ophthalmic Rev. 2012, 6, 98. [CrossRef]

146. McCafferty, S.; Harris, A.; Kew, C.; Kassm, T.; Lane, L.; Levine, J.; Raven, M. Pseudophakic Pseudophakic cystoid macular edema prevention and risk factors; prospective study with adjunctive once daily topical nepafenac $0.3 \%$ versus placebo. BMC Ophthalmol. 2017, 17, 16. [CrossRef]

147. Eriksson, U.; Alm, A.; Bjärnhall, G.; Granstam, E.; Matsson, A.W. Macular edema and visual outcome following cataract surgery in patients with diabetic retinopathy and controls. Graefe's Arch. Clin. Exp. Ophthalmol. 2011, 249, 349-359. [CrossRef]

148. Wielders, L.H.P.; Lambermont, V.A.; Schouten, J.S.A.G.; Van Den Biggelaar, F.J.H.M.; Worthy, G.; Simons, R.W.P.; Winkens, B.; Nuijts, R.M.M.A. Prevention of cystoid macular edema after cataract surgery in nondiabetic and diabetic patients: A systematic review and meta-analysis. Am. J. Ophthalmol. 2015, 160, 968-981. [CrossRef]

149. Khambhiphant, B.; Liumsirijarern, C.; Saehout, P. The effect of Nd: YAG laser treatment of posterior capsule opacification on anterior chamber depth and refraction in pseudophakic eyes. Clin. Ophthalmol. 2015, 9, 557-561. [CrossRef]

150. Kiziltoprak, H.; Tekin, K.; Inanc, M.; Goker, Y.S. Cataract in diabetes mellitus. World J. Diabetes 2019, 10, 140-153. [CrossRef]

151. Praveen, M.R.; Vasavada, A.R.; Shah, G.D.; Shah, A.R.; Khamar, B.M.; Dave, K.H. A prospective evaluation of posterior capsule opacification in eyes with diabetes mellitus: A case-control study. Eye 2014, 28, 720-727. [CrossRef]

152. Donnenfeld, E.; Holland, E. Dexamethasone Intracameral Drug-Delivery Suspension for Inflammation Associated with Cataract Surgery: A Randomized, Placebo-Controlled, Phase III Trial. Ophthalmology 2018, 125, 799-806. [CrossRef]

153. Pimenta, A.F.R.; Serro, A.P.; Colaço, R.; Chauhan, A. Drug delivery to the eye anterior chamber by intraocular lenses: An in vivo concentration estimation model. Eur. J. Pharm. Biopharm. 2018, 133, 63-69. [CrossRef]

154. Morarescu, D.; West-Mays, J.A.; Sheardown, H.D. Effect of delivery of MMP inhibitors from PDMS as a model IOL material on PCO markers. Biomaterials 2010, 31, 2399-2407. [CrossRef]

155. Yu, N.; Fang, F.; Wu, B.; Zeng, L.; Cheng, Y. State of the art of intraocular lens manufacturing. Int. J. Adv. Manuf. Technol. 2018, 98, 1103-1130. [CrossRef]

156. Tan, X.; Zhan, J.; Zhu, Y.; Cao, J.; Wang, L.; Liu, S.; Wang, Y.; Liu, Z.; Qin, Y.; Wu, M.; et al. Improvement of Uveal and Capsular Biocompatibility of Hydrophobic Acrylic Intraocular Lens by Surface Grafting with 2-Methacryloyloxyethyl PhosphorylcholineMethacrylic Acid Copolymer. Sci. Rep. 2017, 7, 40462. [CrossRef] 
157. Huang, Y.S.; Bertrand, V.; Bozukova, D.; Pagnoulle, C.; Labrugère, C.; De Pauw, E.; De Pauw-Gillet, M.C.; Durrieu, M.C. RGD surface functionalization of the hydrophilic acrylic intraocular lens material to control posterior capsular opacification. PLoS ONE 2014, 9, e114973. [CrossRef]

158. Tetz, M.; Jorgensen, M.R. New Hydrophobic IOL Materials and Understanding the Science of Glistenings. Curr. Eye Res. 2015, 40, 969-981. [CrossRef]

159. Molokhia, S.A.; Thomas, S.C.; Garff, K.J.; Mandell, K.J.; Wirostko, B.M. Anterior eye segment drug delivery systems: Current treatments and future challenges. J. Ocul. Pharmacol. Ther. 2013, 29, 92-105. [CrossRef]

160. Ljubimov, A.V. Diabetic complications in the cornea. Vision Res. 2017, 139, 138-152. [CrossRef]

161. Clayton, J.A. Dry eye. N. Engl. J. Med. 2018, 378, 2212-2223. [CrossRef]

162. Findlay, Q.; Reid, K. Dry eye disease: When to treat and when to refer. Aust. Prescr. 2018, 41, 160-163. [CrossRef]

163. Karsten, E. Diversity of Microbial Species Implicated in Keratitis: A Review. Open Ophthalmol. J. 2012, 6, 110-124. [CrossRef]

164. Kuruvilla, S.; Peter, J.; David, S.; Premkumar, P.S.; Ramakrishna, K.; Thomas, L.; Vedakumar, M.; Peter, J.V. Incidence and risk factor evaluation of exposure keratopathy in critically ill patients: A cohort study. J. Crit. Care 2015, 30, 400-404. [CrossRef]

165. Dutescu, R.M.; Panfil, C.; Schrage, N. Osmolarity of prevalent eye drops, side effects, and therapeutic approaches. Cornea 2015, 34, 560-566. [CrossRef]

166. Daphna, O.; Mimouni, M.; Keshet, Y.; Ben Ishai, M.; Barequet, I.S.; Knyazer, B.; Mrukwa-Kominek, E.; Zarnowski, T.; Chen-Zion, M.; Marcovich, A. Therapeutic HL-Contact Lens versus Standard Bandage Contact Lens for Corneal Edema: A Prospective, Multicenter, Randomized, Crossover Study. J. Ophthalmol. 2020, 2020, 8410920. [CrossRef]

167. Siu, G.D.J.Y.; Young, A.L.; Jhanji, V. Alternatives to corneal transplantation for the management of bullous keratopathy. Curr. Opin. Ophthalmol. 2014, 25, 347-352. [CrossRef]

168. Soh, Y.Q.; Kocaba, V.; Weiss, J.S.; Jurkunas, U.V.; Kinoshita, S.; Aldave, A.J.; Mehta, J.S. Corneal dystrophies. Nat. Rev. Dis. Prim. 2020, 6, 46. [CrossRef]

169. Han, S.B.; Yang, H.K.; Hyon, J.Y. Influence of diabetes mellitus on anterior segment of the eye. Clin. Interv. Aging 2019, 14, 53-63. [CrossRef]

170. Abdelkader, H.; Patel, D.V.; Mcghee, C.N.; Alany, R.G. New therapeutic approaches in the treatment of diabetic keratopathy: A review. Clin. Exp. Ophthalmol. 2011, 39, 259-270. [CrossRef]

171. de Alves, M.C.; Carvalheira, J.B.; Módulo, C.M.; Rocha, E.M. Tear film and ocular surface changes in diabetes mellitus. Arq. Bras. Oftalmol. 2008, 71, 96-103. [CrossRef] [PubMed]

172. Zidan, G.; Rupenthal, I.D.; Greene, C.; Seyfoddin, A. Medicated ocular bandages and corneal health: Potential excipients and active pharmaceutical ingredients. Pharm. Dev. Technol. 2018, 23, 255-260. [CrossRef] [PubMed]

173. Misra, S.L.; Patel, D.V.; McGhee, C.N.J.; Pradhan, M.; Kilfoyle, D.; Braatvedt, G.D.; Craig, J.P. Peripheral neuropathy and tear film dysfunction in type 1 diabetes mellitus. J. Diabetes Res. 2014, 2014, 848659. [CrossRef]

174. Shih, K.C.; Lam, K.L.; Tong, L. A systematic review on the impact of diabetes mellitus on the ocular surface. Nutr. Diabetes 2017, 7, e251. [CrossRef]

175. Ali, M.; Byrne, M.E. Controlled release of high molecular weight hyaluronic acid from molecularly imprinted hydrogel contact lenses. Pharm. Res. 2009, 26, 714-726. [CrossRef]

176. Maulvi, F.A.; Soni, T.G.; Shah, D.O. Extended release of hyaluronic acid from hydrogel contact lenses for dry eye syndrome. J. Biomater. Sci. Polym. Ed. 2015, 26, 1035-1050. [CrossRef]

177. Maulvi, F.A.; Shaikh, A.A.; Lakdawala, D.H.; Desai, A.R.; Pandya, M.M.; Singhania, S.S.; Vaidya, R.J.; Ranch, K.M.; Vyas, B.A.; Shah, D.O. Design and optimization of a novel implantation technology in contact lenses for the treatment of dry eye syndrome: in vitro and in vivo evaluation. Acta Biomater. 2017, 53, 211-221. [CrossRef]

178. White, C.J.; Dipasquale, S.A.; Byrne, M.E. Controlled Release of Multiple Therapeutics from Silicone Hydrogel Contact Lenses. Optom. Vis. Sci. 2016, 93, 377-386. [CrossRef]

179. Kim, G.; Kim, H.J.; Noh, H. pH sensitive soft contact lens for selective drug-delivery. Macromol. Res. 2018, 26, 278-283. [CrossRef]

180. Pitt, W.G.; Jack, D.R.; Zhao, Y.; Nelson, J.L.; Pruitt, J.D. Loading and release of a phospholipid from contact lenses. Optom. Vis. Sci. 2011, 88, 502-506. [CrossRef]

181. Pitt, W.G.; Jack, D.R.; Zhao, Y.; Nelson, J.L.; Pruitt, J.D. Transport of phospholipid in silicone hydrogel contact lenses. J. Biomater. Sci. Polym. Ed. 2012, 23, 527-541. [CrossRef]

182. Pitt, W.G.; Zhao, Y.; Jack, D.R.; Perez, K.X.; Jones, P.W.; Marelli, R.; Nelson, J.L.; Pruitt, J.D. Extended elution of phospholipid from silicone hydrogel contact lenses. J. Biomater. Sci. Polym. Ed. 2015, 26, 224-234. [CrossRef]

183. Chen, W.; Zhang, X.; Li, J.; Wang, Y.; Chen, Q.; Hou, C.; Al, E. Efficacy of osmoprotectants on prevention and treatment of murine dry eye. Investig. Ophth Vis. Sci. 2013, 54, 6287-6297. [CrossRef]

184. Hsu, K.H.; De La Jara, P.L.; Ariyavidana, A.; Watling, J.; Holden, B.; Garrett, Q.; Chauhan, A. Release of betaine and dexpanthenol from vitamin E modified silicone-hydrogel contact lenses. Curr. Eye Res. 2015, 40, 267-273. [CrossRef]

185. Zhang, X.; Zhao, L.; Deng, S.; Sun, X.; Wang, N. Dry Eye Syndrome in Patients with Diabetes Mellitus: Prevalence, Etiology, and Clinical Characteristics. J. Ophthalmol. 2016, 2016, 1-7. [CrossRef]

186. Guzman-Aranguez, A.; Fonseca, B.; Carracedo, G.; Martin-Gil, A.; Martinez-Aguila, A.; Pintor, J. Dry Eye Treatment Based on Contact Lens Drug Delivery: A Review. Eye Contact Lens 2016, 42, 280-288. [CrossRef] 
187. Phan, C.M.; Subbaraman, L.; Jones, L. Contact lenses for antifungal ocular drug delivery: A review. Expert Opin. Drug Deliv. 2014, 11,537-546. [CrossRef]

188. Garg, P.; Venuganti, V.V.K.; Roy, A.; Roy, G. Novel drug delivery methods for the treatment of keratitis: Moving away from surgical intervention. Expert Opin. Drug Deliv. 2019, 16, 1381-1391. [CrossRef]

189. Liu, X.; Chen, J.; Qu, C.; Bo, G.; Jiang, L.; Zhao, H.; Zhang, J.; Lin, Y.; Hua, Y.; Yang, P.; et al. A Mussel-Inspired Facile Method to Prepare Multilayer-AgNP-Loaded Contact Lens for Early Treatment of Bacterial and Fungal Keratitis. ACS Biomater. Sci. Eng. 2018, 4, 1568-1579. [CrossRef]

190. Aveyard, J.; Deller, R.C.; Lace, R.; Williams, R.L.; Kaye, S.B.; Kolegraff, K.N.; Curran, J.M.; D’Sa, R.A. Antimicrobial Nitric Oxide Releasing Contact Lens Gels for the Treatment of Microbial Keratitis. ACS Appl. Mater. Interfaces 2019, 11, 37491-37501. [CrossRef]

191. Hewitt, M.G.; Morrison, P.W.J.; Boostrom, H.M.; Morgan, S.R.; Fallon, M.; Lewis, P.N.; Whitaker, D.; Brancale, A.; Varricchio, C.; Quantock, A.J.; et al. In Vitro Topical Delivery of Chlorhexidine to the Cornea: Enhancement Using Drug-Loaded Contact Lenses and $\beta$-Cyclodextrin Complexation, and the Importance of Simulating Tear Irrigation. Mol. Pharm. 2020, 17, 1428-1441. [CrossRef]

192. Huang, J.F.; Zhong, J.; Chen, G.P.; Lin, Z.T.; Deng, Y.; Liu, Y.L.; Cao, P.Y.; Wang, B.; Wei, Y.; Wu, T.; et al. A Hydrogel-Based Hybrid Theranostic Contact Lens for Fungal Keratitis. ACS Nano 2016, 10, 6464-6473. [CrossRef]

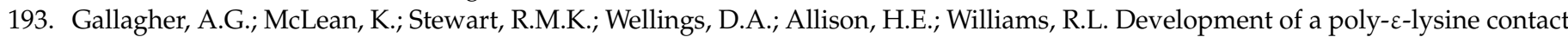
lens as a drug delivery device for the treatment of fungal keratitis. Investig. Ophthalmol. Vis. Sci. 2017, 58, 4499-4505. [CrossRef]

194. Phan, C.M.; Bajgrowicz, M.; Gao, H.; Subbaraman, L.N.; Jones, L.W. Release of fluconazole from contact lenses using a novel in vitro eye model. Optom Vis. Sci. 2016, 93, 387-394. [CrossRef]

195. Jaishankar, D.; Buhrman, J.S.; Valyi-Nagy, T.; Gemeinhart, R.A.; Shukla, D. Extended release of an anti-heparan sulfate peptide from a contact lens suppresses corneal herpes simplex virus-1 infection. Investig. Ophthalmol. Vis. Sci. 2016, 57, 169-180. [CrossRef]

196. Varela-Garcia, A.; Gomez-Amoza, J.L.; Concheiro, A.; Alvarez-Lorenzo, C. Imprinted contact lenses for ocular administration of antiviral drugs. Polymers 2020, 12, 2026. [CrossRef]

197. Jacob, S.; Kumar, D.A.; Agarwal, A.; Basu, S.; Sinha, P.; Agarwal, A. Contact lens-assisted collagen cross-linking (CACXL): A new technique for cross-linking thin corneas. J. Refract. Surg. 2014, 30, 366-372. [CrossRef]

198. Kubrak-Kisza, M.; Kisza, K.J.; Misiuk-Hojło, M. Corneal Cross-Linking: An Example of Photoinduced Polymerization as a Treatment Modality in Keratoconus. Polim. Med. 2016, 46, 89-94. [CrossRef]

199. Malhotra, C.; Jain, A.K.; Gupta, A.; Ram, J.; Ramatchandirane, B.; Dhingra, D.; Sachdeva, K.; Kumar, A. Demarcation line depth after contact lens-assisted corneal crosslinking for progressive keratoconus: Comparison of dextran-based and hydroxypropyl methylcellulose-based riboflavin solutions. J. Cataract Refract. Surg. 2017, 43, 1263-1270. [CrossRef]

200. Han, S.B.; Liu, Y.-C.; Mohamed-Noriega, K.; Mehta, J.S. Application of Novel Drugs for Corneal Cell Regeneration. J. Ophthalmol. 2018, 2018, 1-9. [CrossRef]

201. Wollensak, G.; Spörl, E.; Herbst, H. Biomechanical efficacy of contact lens-assisted collagen cross-linking in porcine eyes. Acta Ophthalmol. 2019, 97, e84-e90. [CrossRef] [PubMed]

202. Holland, S.; Morck, D.; Schultz, C. Treatment of corneal defects with delayed re-epithelization with a medical device/drug delivery system for epidermal growth factor. Clin. Exp. Ophthalmol. 2012, 40, 662-668. [CrossRef] [PubMed]

203. Sandri, G.; Bonferoni, M.C.; Rossi, S.; Delfino, A.; Riva, F.; Icaro Cornaglia, A.; Marrubini, G.; Musitelli, G.; Del Fante, C.; Perotti, C.; et al. Platelet lysate and chondroitin sulfate loaded contact lenses to heal corneal lesions. Int. J. Pharm. 2016, 509, 188-196. [CrossRef]

204. Nakahara, M.; Miyata, K.; Otani, S.; Miyai, T.; Nejima, R.; Yamagami, S.; Amano, S. A randomised, placebo controlled clinical trial of the aldose reductase inhibitor CT-112 as management of corneal epithelial disorders in diabetic patients. Br. J. Ophthalmol. 2005, 89, 266-268. [CrossRef]

205. Dogru, M.; Kojima, T.; Simsek, C.; Tsubotav, K. Potential role of oxidative stress in ocular surface inflammation and dry eye disease. Investig. Ophthalmol. Vis. Sci. 2018, 59, DES163-DES168. [CrossRef]

206. Shoham, A.; Hadziahmetovic, M.; Dunaief, J.L.; Mydlarski, M.B.; Schipper, H.M. Oxidative stress in diseases of the human cornea. Free Radic. Biol. Med. 2008, 45, 1047-1055. [CrossRef]

207. Agrahari, V.; Agrahari, V.; Mandal, A.; Pal, D.; Mitra, A.K. How are we improving the delivery to back of the eye? Advances and challenges of novel therapeutic approaches. Expert Opin. Drug Deliv. 2017, 14, 1145-1162. [CrossRef]

208. Rastogi, N.; Smith, R.T. Association of age-related macular degeneration and reticular macular disease with cardiovascular disease. Surv Ophthalmol. 2016, 61, 422-433. [CrossRef]

209. Mehta, S. Age-Related Macular Degeneration. Prim. Care-Clin. Off. Pract. 2015, 42, 377-391. [CrossRef]

210. Dedania, V.S.; Grob, S.; Zhang, K.; Bakri, S.J. Pharmacogenomics of response to anti-vegf therapy in exudative age-related macular degeneration. Retina 2015, 35, 381-391. [CrossRef]

211. Davidson, J.A.; Ciulla, T.A.; McGill, J.B.; Kles, K.A.; Anderson, P.W. How the diabetic eye loses vision. Endocrine 2007, 32, 107-116. [CrossRef] [PubMed]

212. Simó, R.; Hernández, C. Neurodegeneration in the diabetic eye: New insights and therapeutic perspectives. Trends Endocrinol. Metab. 2014, 25, 23-33. [CrossRef] [PubMed]

213. Christopher, K.; Chauhan, A. Contact Lens Based Drug Delivery to the Posterior Segment Via Iontophoresis in Cadaver Rabbit Eyes. Pharm. Res. 2019, 36, 87. [CrossRef] 
214. Molokhia, S.A.; Sant, H.; Simonis, J.; Bishop, C.J.; Burr, R.M.; Gale, B.K.; Ambati, B.K. The capsule drug device: Novel approach for drug delivery to the eye. Vis. Res. 2010, 50, 680-685. [CrossRef]

215. Lanier, O.L.; Christopher, K.G.; Macoon, R.M.; Yifan Yu, P.; Sekar, P.; Chauhan, A. Commercialization challenges for drug eluting contact lenses. Expert Opin. Drug Deliv. 2020, 17, 1133-1149. [CrossRef] 